\title{
PSYCHE
}

\begin{tabular}{lll}
\hline Vol. 90 & 1983 & No.1-2 \\
\hline
\end{tabular}

\section{STUDIES ON \\ UPPER CARBONIFEROUS INSECTS: \\ 1. THE GERARIDAE (ORDER PROTORTHOPTERA)}

\author{
By Laurie Burnham \\ Department of Entomology, Cornell University, \\ Ithaca, New York 14853; \\ and Museum of Comparative Zoology, Harvard University, \\ Cambridge, Massachusetts 02138*
}

\section{INTRODUCTION}

Despite the importance of the order Protorthoptera, ${ }^{1}$ little is known about its evolutionary history. While recent workers have emphasized morphological and taxonomic diversity in the group (Carpenter, 1971, 1977; Wootton, 1981), no one has undertaken serious revisionary study at the family level. As a consequence, our understanding of relationships within the order, as well as relationships of the Protorthoptera to other Paleozoic insects, is rudimentary at best. Clearly, revisionary studies on this group are badly needed.

We know that the Protorthoptera first appear in the fossil record at the base of the Upper Carboniferous (Namurian Stage) and apparently flourished for 80 million years before becoming extinct at the end of the Permian. We also know that they were remarkably

\footnotetext{
'It was one of the dominant orders of the Paleozoic (exceeding all other insects both in number of species and in number of individuals), and is considered by many to be ancestral to the Endopterygota (the group to which $90 \%$ of all living insects belong).
}

*Present address.

Manuscript received by the editor March 5, 1983. 
diverse morphologically, and that diversity in the group (sensu lato) far exceeded that of any other Paleozoic order (Carpenter, 1977). Structural modifications normally associated with more recent insects, including brightly patterned wings, raptorial fore legs, and thoracic extensions of various kinds, are found throughout the group.

Despite this fascinating array of characters, Carboniferous Protorthoptera have generated little interest among systematists. This is due, in part, to problems common to all paleoentomological study: an overall lack of material (rarely is a species based on a large series of specimens); preservational quality that ranges from excellent to very poor; and a taxonomy that is highly subjective.

In addition, there are problems unique to the Protorthoptera which make their study particularly difficult. First, they are neopterous, and as a consequence, are most frequently found with their wings superimposed on one another. Interpretation of the venation under these circumstances is not only difficult, but prone to error. Second, the vast majority of Carboniferous Protorthoptera are known from only two localities: Commentry in France, and Mazon Creek in the United States, and were studied primarily by turn-ofthe-century workers. ${ }^{2}$ As new material has become available for study in recent years, the accuracy of much of this earlier work has been questioned.

Finally, there is the problem of variation. Distinguishing specieslevel differences from intraspecific variation in fossils that have such a limited array of characters is not easily resolved. How, for instance, does one recognize sexual dimorphism in a fossil species when there are no genitalia or secondary sexual characters to serve as guidelines? It is not surprising under the circumstances that paleotaxonomy rests largely on subjective reasoning. But this, unfortunately, has its pitfalls.

Previous work on the Geraridae is a case in point. Anton Handlirsch, responsible for most of the earlier work on the family, described a new species of gerarid for every specimen he examined,

2The Permian Protorthoptera are generally much better known than their Carboniferous relatives. This is attributable to the fact that there are more than eight major Permian deposits (including two in the U.S.) at which Protorthoptera have been found. Furthermore, intensive studies on these insects have attracted the attention of such well-known recent workers as Carpenter, Kukalová, and Sharov. 


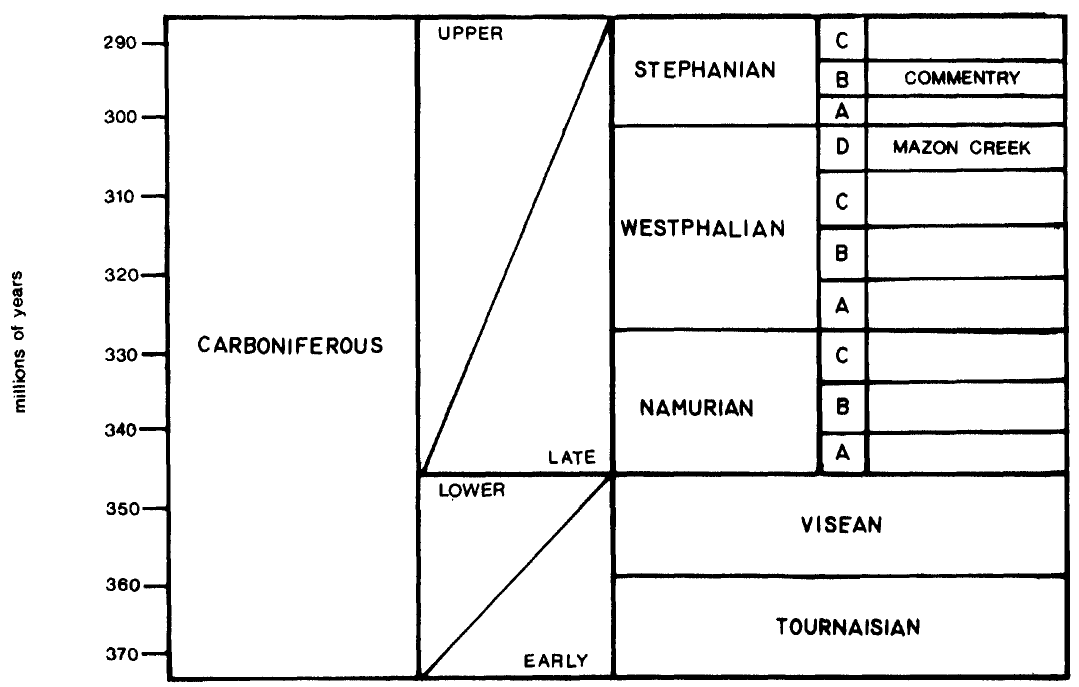

Fig. 1. Geological Time Table of the Carboniferous. Note the different ages of the Commentry and Mazon Creek localities.

basing his taxonomic decisions on small differences in wing venation (Handlirsch, 1906b, 1911, 1922). This approach, while rendering the decision making easier, is nevertheless open to criticism. Studies on intraspecific variation in some Permian Protorthoptera have shown, for instance, that two fore wings belonging to the same specimen will exhibit noticeable differences in venation (Carpenter, 1966). From these findings we can conclude that intraspecific variation in the Protorthoptera was high, and that the variation Handlirsch saw was no greater than that seen in a single specimen. Further evidence that suggests Handlirsch was unrealistic in his representation of species diversity comes from the low probability of finding only one individual per species (for all species collected) in a random sample of living insects. Similarly, we cannot reasonably expect to find only one specimen per species in a paleontological sample, particularly when fossilization was catastrophic (and hence random) as is true for the Mazon Creek biota.

Nevertheless, in spite of these drawbacks to the study of fossil insects, the field can be immensely rewarding. This is because it provides us with concrete evidence (in the form of fossils) of what early insect life was like. Without such proof, we would be guided 
only by our imagination, and having this proof provides a base on which insect phylogeny and early insect evolution can be reconstructed.

Clearly, revisionary studies on Paleozoic insects are important. Fortunately, recent revisional work by Carpenter has greatly increased our knowledge of certain Paleozoic orders (i.e., the Paleodictyoptera, Megasecoptera, Diaphanopterodea, Protodonata, and Caloneurodea), but much work on the Protorthoptera remains. This revision of the family Geraridae is, at least, a beginning and is intended to be the first in a series of family-level studies on Upper Carboniferous Protorthoptera.

Selection of the Geraridae as a starting point was influenced, ultimately, by two factors: 1) it is typical of many of the families in the Protorthoptera, having last been studied in the early part of this century (despite the discovery since then of new material assignable to the family); and 2) the Geraridae are morphologically most unusual insects. They were large (up to $75 \mathrm{~mm}$ in body length), and had as their single most distinctive attribute, a prothorax that was elongate, flask-shaped, and adorned with long, numerous spines. These spines gave them the appearance of walking pincushions, and presumably provided some defense against vertebrate predators.

The systematic importance of the family plus the impact this work has on current classifications of the Protorthoptera will be discussed in subsequent pages. The remaining sections of this paper cover (in the following order): the systematics of the Geraridae; paleoecological differences between the two localities at which gerarids have been found (Mazon Creek and Commentry); and the significance of this study relative to phylogenetic relationships within the Protorthoptera.

\section{Systematics}

\section{MATERials AND Methods}

The fossils examined for this study occur mostly as impressions (imprints in a sedimentary matrix devoid of organic matter) but some occur as compressions (in these, organic matter is present, but usually coalified). Both types of fossils were prepared by degagement, ${ }^{3}$ i.e., an uncovering of the fossil by removal of the overlying rock matrix. This is generally done using a fine pneumatic drill and

${ }^{3}$ From the French verb degager meaning to disengage, extricate, or get clear. 
compressed air gun. The technique is particularly effective at revealing regions of an insect's body (wing tips, legs, etc.) that are found beneath the bedding plane. Following degagement, specimens were studied under a Wild M-5 stereo microscope and photographed with a Zeiss 4" by 5" format camera.

Drawings were made of each fossil by tracing a general outline from a photographic enlargement. Verification of detail was made by referring back to the specimens and examining them frequently under the microscope. The most complete reconstructions (e.g., fig. 2 of $G$. danielsi) were possible for those species that consist of a large series of specimens. This is because one fossil rarely displays all characters equally well, and, therefore, the larger the number of specimens, the greater the likelihood of multiple character preservation.

Type specimens, including the holotypes, for all taxa considered in this revisionary study were borrowed and examined using the above methods. Pre-existing taxa were synonymized whenever possible, a decision based on the assumption that (for reasons cited earlier) intraspecific variation in the Protorthoptera is great. Characters of greatest taxonomic importance were venation and body size and shape, particularly with respect to the prothorax. In situations where clearcut characters were lacking, as is true for several of the Mazon Creek gerarids, I relied solely on size as a criterion for specific assignment. While this may result in the recognition of some dubious species, it seems preferable to relegating certain specimens to incertae sedis status.

Since wing venation is such an important taxonomic tool both in paleoentomological and extant systematic study, it is surprising that until recently no standardized wing terminology has been adopted. This is particularly unfortunate for the Protorthoptera, $80 \%$ of which have been described on the basis of wings alone. Inroads have recently been made into this problem primarily by the efforts of Carpenter in the United States and Wootton in Great Britain. Both have stressed (Carpenter, 1966; Wootton, 1979, 1981) the importance of a standardized venational nomenclature and Wootton (1979) has proposed a terminology modified slightly from the one used previously by Lameere (1922) and Martynov (1924, 1938).

Wootton proposes that the following nine major longitudinal veins be recognized: Costa (C); Subcosta (SC); Radius (R); Radial Sector (RS); Anterior Media (MA); Posterior Media (MP); Anterior Cubitus (CUA); Posterior Cubitus (CUP), and Anals. In light 
of the historical basis for the nomenclature (used extensively in the paleoentomological literature) and its conservatism (it may be used to homologize the wing venation of all insects) I enthusiastically concur with Wootton's recommendations and will employ his system here and in future systematic work.

A total of 58 specimens were made available for study through the loans of various institutions and individuals. These are listed here with their abbreviations:

Field Museum of Natural History (FMNH), Chicago, Illinois, U.S.A. (This includes specimens collected by Jerry Herdina and subsequently acquired by the Field Museum).

Institut de Paléontologie, Muséum National d'Histoire Naturelle (IP), Paris, France.

Museum of Comparative Zoology (MCZ), Cambridge, Massachusetts, U.S.A.

United States National Museum (USNM), Washington, D.C., U.S.A.

Yale Peabody Museum (YPM), New Haven, Connecticut, U.S.A. Daniel Damrow, of Mosinee, Wisconsin. Private collection. (DMRW) (Includes specimens previously in the collection of Walter Dabasinskas).

David Douglass, of Yachats, Oregon. Private collection. (DGLS)

Francis and Terri Wolff, of Port Charlotte, Florida. Private collection (Wolff).

\section{Order Protorthoptera Handlirsch}

Family Geraridae Scudder, 1885

[Nom. correct. Handlirsch, 1906a (ex Gerarina Scudder, 1885)]

Gerarina Scudder 1885:342. Type: Gerarus Scudder.

Geraridae Handlirsch 1906a:146, 1906b:701, 1911:312, 1920:151.

Sthenaropodidae Handlirsch 1906a:141, 1919:37, 1920:150; Sharov 1968:19. Type:

Sthenaropoda Brongniart. NEW SYNONYMY.

Genopterygidae Richardson 1956:41. Type: Genopteryx Scudder. NEW SYNONYmy.

\section{Description}

Fore and hind wings similar in size and shape, but markedly different in venation.

Fore wing: length $35-55 \mathrm{~mm}$, and apparently not coriaceous; costal area broad in basal region, SC simple, terminating in $\mathrm{C} ; \mathrm{R}$ parallel to SC, terminating at wing apex; $\mathrm{RS}$ originating from base 
of $\mathrm{R}$ near midpoint of wing; $\mathrm{M}$ either anastomosing with $\mathrm{RS}$ for a short distance or connecting to it by a cross-vein; CUA strongly developed, arising from base of M; CUP forked, arising independently from wing base.

Hind wing: length $30-48 \mathrm{~mm}$; costal area not as broad as in fore wing; SC simple, terminating in $\mathrm{C}$; $\mathrm{R}$ parallel to $\mathrm{SC}$, terminating at wing apex; RS pectinate, arising from $\mathrm{R}$ near wing base; $\mathrm{M}$ forked, arising near base of RS; CUA and CUP simple and parallel to one another; CUA arising from base of RS near M, CUP arising independently from wing base; anal area unusually reduced; cross veins abundant in both fore and hind wings.

- Body: prothorax elongate, flask-shaped, and distinctively spinose; abdomen cylindrical; antennae filamentous; head small and probably mobile; legs cursorial, tarsi five-segmented.

\section{Diagnosis}

In many ways the Geraridae are typical Orthopteroidea, having mandibulate mouthparts, hypognathous heads, and filamentous antennae. But they differ from other orthopteroids in two important characters: their well-developed prothorax which is armed with spines (the latter reach a length of $10 \mathrm{~mm}$ in $G$. danielsi), and their distinctive fore and hind wing venation. While gerarids can be readily recognized on the basis of the prothorax alone, wing venation is generally a better diagnostic character. Particularly distinctive are the RS-M veins in the fore wing, and the R-RS veins in the hind wing. In the fore wing RS is reduced and $M$ is expanded with 5 to 6 branches. The apical branch of $M$ either anastomoses with RS for a short distance or is connected to it by a short cross vein. In the hind wing, the opposite is true: $M$ is greatly reduced and RS expanded into 5 to 6 branches.

It is worth noting that the anal fan in the hind wing, if present, was very small (see fig. 17). This suggests that in gerarids the fore and hind wings may have functioned equally well in flight, unlike in extant Orthoptera, which rely primarily on expanded hind wings for flight propulsion. The abdomen is essentially unknown for the family, but was probably shorter than the wings, a claim based on the comparison of wing length to legs, thorax, and head. No cerci are preserved, but because the Geraridae are orthopteroid, it may be assumed that they were present. 


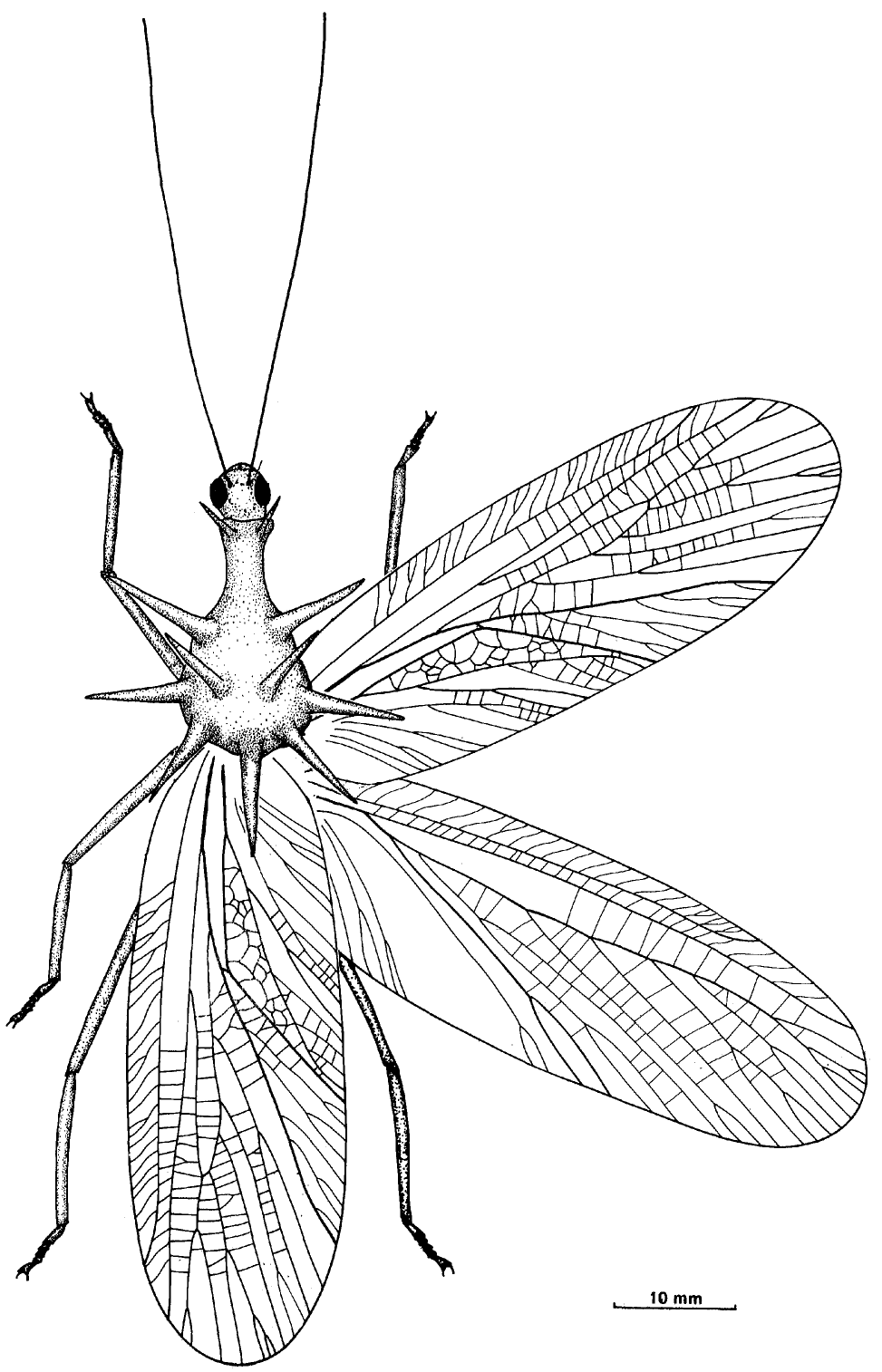

Fig. 2. Gerarus danielsi, composite drawing, based primarily on-specimens FMNH PE 5276, 31973, 32027, 32029; and USNM 31973: 


\section{Remarks}

The family Geraridae was first established by Scudder (1885) for several fossil insects from Mazon Creek noted for their slender bodies, which tapered "greatly anteriorly" (Scudder, 1885:344), and for the distinctive branching pattern of RS in the hind wing. Scudder placed the family in the order Paleodictyoptera, section Neuropteroidea, where it remained until 1906 when Handlirsch erected the order Protorthoptera and transferred the Geraridae to it. ${ }^{4}$ Most of the subsequent work on the family was carried out by Handlirsch who added a total of two new genera and nine new species to it (Handlirsch, 1906a, 1906b, 1911, 1920).

This revision is the first systematic work carried out on the family since then, and rectifies many of the taxonomic errors made by these earlier workers. To a large extent, the mistakes made by Scudder and Handlirsch may be attributed to the limited availability of material at their disposal, and the preservation of most gerarids with all four wings lying over one another. Nevertheless, their errors were of grave consequence. To begin with, neither worker apparently recognized the extent to which intraspecific variation occurs in the family, and therefore each named only monotypic species. But, more importantly, owing to the difficulties of wing overlap, neither Scudder nor Handlirsch correctly interpreted the wing venation of Gerarus; both managed to interpret the venation of one wing (the hind wing) and then assumed that fore and hind wings were identical, although neither actually saw the fore wing.

The advantage of having more material at my disposal made it possible for me to overcome the problems that faced these workers. Certain well-preserved specimens (especially FMNH-PE 5276, 31973, 32027; IP 5, 23) were instrumental in demonstrating the complete venational differences between fore and hind wings. A comparison of figs. $6 \mathrm{a}$ and $6 \mathrm{~b}$ shows how strikingly different the fore wing actually is from the hind wing. This, in itself, was quite a revelation. But it was only later, when searching through the literature looking for venational similarities with other groups, that the

\footnotetext{
${ }_{4}^{4}$ Prior to this, all Carboniferous insects were included in the one order Paleodictyoptera in accordance with Scudder's beliefs that ordinal differentiation had not taken place in the Insecta as early as the Carboniferous. We know, of course, that this was incorrect; a total of 11 orders are now recognized from that Period (Carpenter, 1977; Wootton, 1981).
} 
full significance of the discovery emerged. It became immediately apparent, based on fore wing characters, that the type genus (Sthenaropoda) for the family Sthenaropodidae 5 is inseparable from Gerarus. The consequences of this are twofold: 1) it extends the geographic range of the Geraridae from North America to Europe, strongly suggesting that the family was once large and successful; and 2) the synonymy casts serious doubts on current classifications of Paleozoic orthopteroids such as those proposed by Sharov (1968) and Rasnitsyn (1980). The implications of this are addressed in the discussion section at the end of this paper.

Geological Range: Carboniferous-Westphalian D to Stephanian. Occurrence: Mazon Creek, Illinois, U.S.A.; Commentry, France. TYPE GENUS: Gerarus.

\section{Synonymies}

The families Genopterygidae and Sthenaropodidae are synonymized here with the Geraridae, since I find no unique characters by which to recognize them as independent taxa. All major veins and body characters are in complete agreement with the definition of the Geraridae. Although the Genopterygidae are described from the hind wing alone, and this synonymy may therefore change as additional material is found, the venational similarities between Genopteryx and Gerarus are striking (see fig. 7). This, in my mind, is sufficient reason at this time to synonymize these families. The synonymy of the Sthenaropodidae with the Geraridae is based not only on the venation of both wings, but also on the prothorax (complete with spines) and body size. The two families are so similar in character that synonymy at the species level could almost be justified were it not for their separation both geologically and geographically.

\footnotetext{
sThe Sthenaropodidae, like the Geraridae, were the focus of taxonomic work largely at the turn of the century. Brongniart first described Sthenaropoda (based on $S$. fischeri) in 1885 and placed it with a series of other Carboniferous Protorthoptera in the family Paleoacridiodea. Eight years later he synonymized Sthenaropoda with Oedischia (now recognized as belonging to the Orthoptera), believing their differences too slight to warrant generic separation. In 1906 Handlirsch restored the genus Sthenaropoda and placed it in its own family. His decision was later defended by both Lameere (1917) and Sharov (1968), who felt that the oedischiids, by virtue of their saltatorial legs, were true Orthoptera, and that the sthenaropodids, which lacked well-developed jumping legs, were clearly members of the Protorthoptera. The ramifications of this are discussed in the concluding pages of this paper.
} 

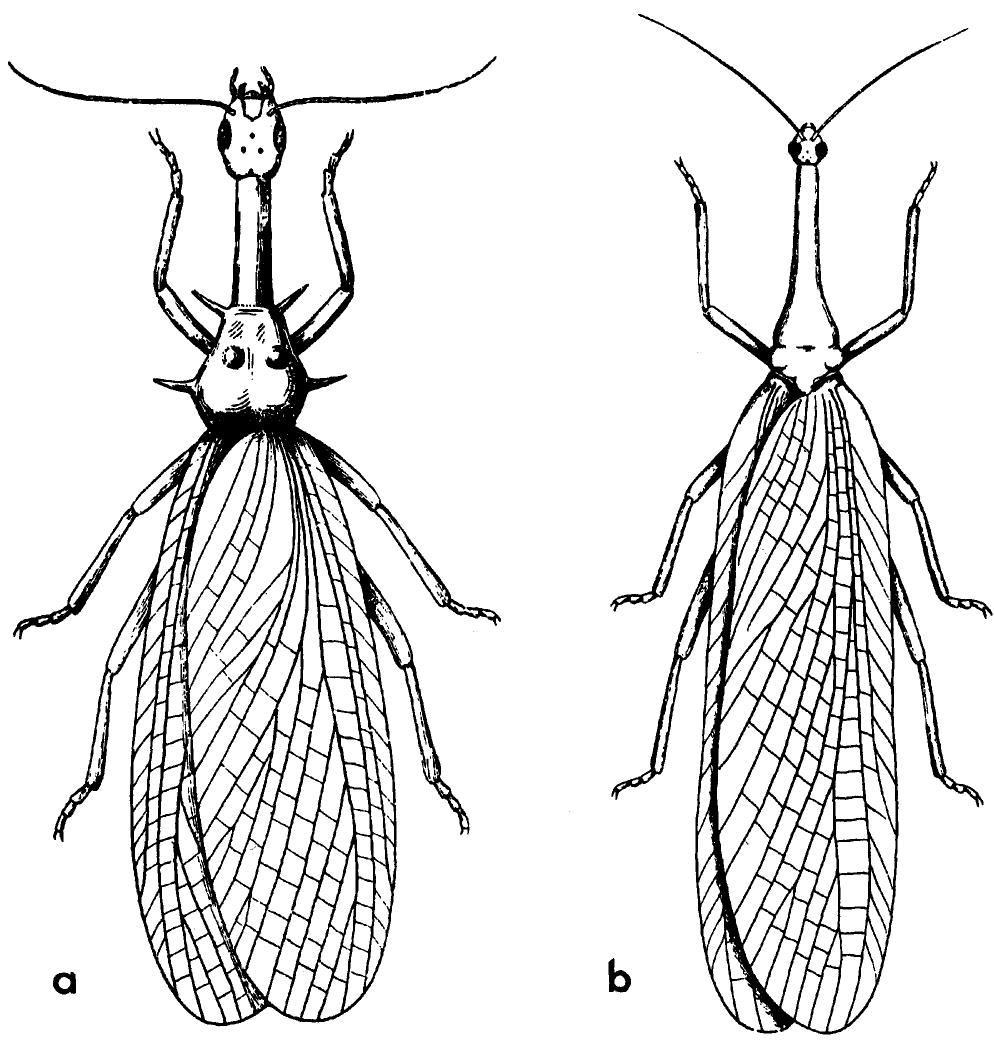

Fig. 3. Handlirsch's reconstructions of two species of Gerarus. a. G. danielsi; b. G. collaris (=longicollis). (From Handlirsch, 1920:152,153). 


\section{Genus Gerarus}

Gerarus Scudder 1885:344; Handlirsch 1906a:147, 1906b:702, 1911: 313, 1919:38. Type: Gerarus vetus Scudder (original designation).

Sihenaropoda Brongniart 1885:59; Handlirsch 1906a:148, 1906b: 704, 1919:30. Type: Sthenaropoda fischeri (original designation). NEW SYNONYMY ${ }^{\circ}$

Genopteryx Scudder 1885:327; Handlirsch 1906a:148, 1906b:704, 1919:30. Type: Genopteryx constricta (original designation). NEW SYNONYMY.?

Archaeacridites Meunier 1909a:39, 1909c:145; Handlirsch 1919:39. Type: Archaeacridites bruesi (original designation). NEW SYNONYMY.

Rossites Richardson 1956:44. Type: Rossites inopinus (original designation). NEW SYNONYMY.

\section{Description}

Fore wing: membranous, larger than hind wing, rounded at apex; SC long, weakly turning anteriorly to fuse with $\mathrm{C}$ at point three-fourths to two-thirds the length of the wing; $\mathrm{R}$ parallel to $\mathrm{SC}$, terminating in $\mathrm{C}$ slightly anteriorad to wing apex. Fore wings differ from hind wings in the following veins: in the fore wing, RS branches from $\mathrm{R}$ in the basal third of the wing, and bifurcates two or three times. $M$ four- or five-branched, either connecting to RS by a cross vein or fusing with it; CUA coalesces with $M$ for short distance at wing base and may be weakly branched; CUP simple, elbowed towards CUA; network of anal veins present.

Hind wing: RS has three to six distinct pectinate branches and does not fuse with $\mathrm{M}$; $\mathrm{M}$ multiply branched, arising from RS; CUA

\footnotetext{
'Some doubt exists concerning the date of publication of this paper with respect to Scudder's 1885 article, but I have concluded for the following reasons that Scudder had priority of publication: 1) Although we do not know the month of publication for Brongniart's paper, we do know that Scudder's was published early in April, 1885. Unfortunately, attempts to obtain the exact date of publication for Brongniart's article from the Muséum d'Histoire Naturelle de Rouen and the Societe des Amis des Sciences Naturelles de Rouen have met with no response. 2) Citations of these two papers (e.g., Handlirsch, 1906a, 1922) have consistently listed Scudder's paper before Brongniart's. 3) Scudder's 1885 account of Gerarus includes a full description, figures, and designation of a type species ( $G$. vetus), whereas Brongniart's paper only mentions Sthenaropoda and gives no formal description.
}

\footnotetext{
${ }^{7}$ Gerarus and Genoptery $x$ were named and described by Scudder in the same paper (1885). In accordance with the I.C.Z.N. procedures, and as the first reviser, I have treated Genopteryx as the junior synonym of Gerarus, the better known and larger genus.
} 
simple or with one bifurcation; CUP simple and parallel to CUA; anal area slightly expanded, but unusually reduced for the Orthopteroidea. See fig. 17.

\section{Diagnosis}

Gerarus may be distinguished from the other genera in the Geraridae (Nacekomia, Progenentomum, Genentomum and Gerarulus) by size (members of this genus are large, fore wing is $40 \mathrm{~mm}$ to 55 $\mathrm{mm}$ in length); and the nature of the RS and $M$ veins in the fore wing. In Gerarus RS branches two or three times; in Progenentomum, it branches at least four times. $\mathrm{M}$ in Gerarus is four- or five-branched, and either coalesces with RS for a short distance or is connected to it by a well-developed cross vein. In contrast, $\mathrm{M}$ in Nacekomia is distinct from RS, and in Genentomum, M is only three-branched and these branches are distinctly parallel to one another. Other characters such as the shape of the thorax and number of prothoracic spines may ultimately prove important in distinguishing these genera from one another, but as yet, we lack the well-preserved specimens necessary for separating all four genera in the family on the basis of such additional characters.

\section{Remarks}

Handlirsch (1911:313) characterized Gerarus by its prothorax, described as "a broad base, either provided with tubercles or smooth, but in every case, produced into a long neck-like part bearing the head." While he was correct about the nature of the "neck," he was incorrect in his assessment of the "tubercles," which were presumably present in all adult gerarids as fully produced spines, not tubercles. He was also slightly inaccurate in describing the prothorax as "a broad base." This study has shown the width of the prothorax to vary from $5 \mathrm{~mm}$ to $13 \mathrm{~mm}$ depending on the species. A better description for the genus is one based on wing venation.

Geological Range: Upper Carboniferous-Westphalian D to Stephanian. Occurrence: Mazon Creek, Illinois, U.S.A.; Commentry, France. TYPE SPECIES: Gerarus vetus.

\section{Synonymies}

As indicated in previous pages, clarification of the venation of both fore and hind wings has led to several important synonymies. A comparison of Sthenaropoda with Gerarus reveals that the venational differences lie largely in the number of branches of $M$ and 
this, in my opinion, does not justify distinction above the species level. Similarly, Archaeacridites, lacking distinct venational characters, cannot be separated from Gerarus.

I am also synonymizing two genera from the order Caloneurodea with Gerarus: Genopteryx and Rossites, for which Richardson (1956) erected the family Genopterygidae. Genoptery'x, originally described by Scudder (1885), and placed in the family Homothetidae, was transferred subsequently to the Geraridae by Handlirsch (1906a). Richardson (1956:41) removed Genopteryx from the Geraridae and placed it in the order Caloneurodea. He did so on the basis of its "heavy cross veins and the close straight parallel CUA and CUP" these being the "two characters regarded by Carpenter (1943) as prescribing inclusion in the order Caloneurodea." Richardson then states that "Rossites has delicate cross veins and its CUA deviates from strict parallelism with CUP, yet the venation is nearly identical with that of Genopteryx," and for that reason placed the two genera in the same family. While these genera do seem to belong together, I see no reason to include them in the Caloneurodea. One result of the present study was the discovery that CUA and CUP are typically parallel in the hind wing of the gerarids, and that placement and number of the cross veins is variable. Therefore, with the disappearance of the supposed diagnostic venational characters that Richardson used to justify their inclusion in the Caloneurodea and the discovery of synapomorphies by which they may be linked to Gerarus, I feel that there is every reason to include these species in the Geraridae. It is interesting to note, however, that the parallel positions of CUA and CUP, characteristic of this family, may ultimately indicate a closer relationship with the Caloneurodea than previously recognized.

Gerarus vetus

Figures 4 and 5

Gerarus vetus Scudder 1885:344, 1890:308; Handlirsch 1906a:147, 1906b:702, 1919:30.

\section{Description}

Fore wing: length $45-55 \mathrm{~mm}$, width $13 \mathrm{~mm}$; RS two- to three-branched, fusing with $M$ for short distance at point where $M$ elbows towards RS; M three-branched; CUA simple, CUP forked. 


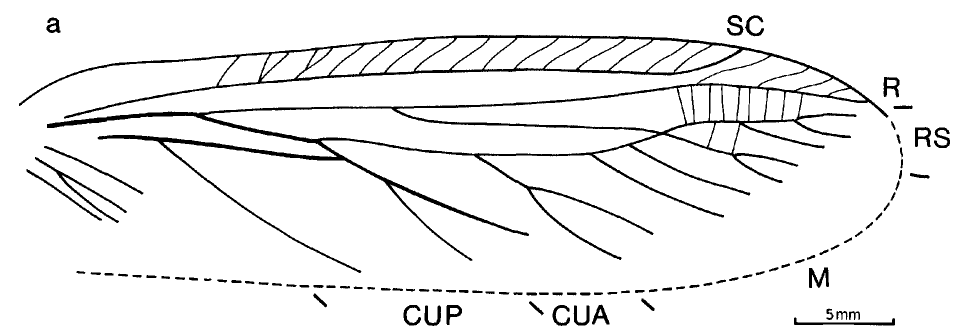

b

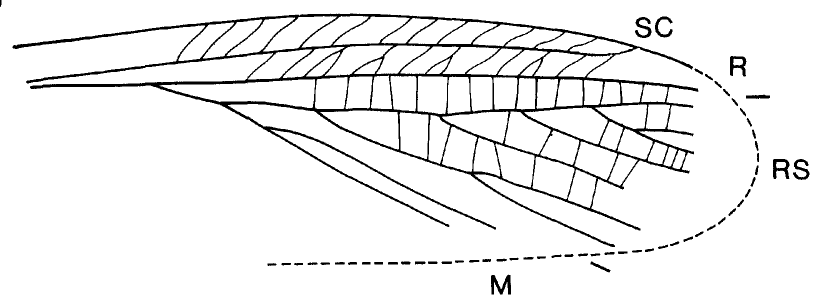

Fig. 4. Gerarus vetus, a. composite drawing of the fore wing, based on DGLS I and USNM 38136. b. composite drawing of the hind wing, based on DGLS I and USNM 38136.

Hind wing: length $42-50 \mathrm{~mm}$, width $11-12 \mathrm{~mm}$; RS at least four-branched; $M$ forked; CUA and CUP not known.

Body: prothorax much smaller in this species than in $G$. danielsi. Width about $5 \mathrm{~mm}$ at its widest point, length $10-15 \mathrm{~mm}$. Largest measurable spine $7 \mathrm{~mm}$. Unfortunately, the arrangement and number of spines in this species is uncertain, but nine are expected in keeping with the genus. Head small, 4-5 $\mathrm{mm}$ in length. Coxae possibly enlarged; tibiae and femora long and slender.

\section{Diagnosis}

This species is distinguished from $G$. danielsi on the basis of its long and slender appearance, its diminutive prothorax and narrow wings. Unfortunately, the venation is not sufficiently preserved in any of the specimens assigned to this species to be useful as a diagnostic character. Although body length is intermediate between that of $G$. danielsi and $G$. collaris, this species is clearly more slender than the other species in the genus. Compare fig. 5 with figs. 9 and 13.

Geological range: Westphalian D. Occurrence: Mazon Creek, Illinois, U.S.A. 


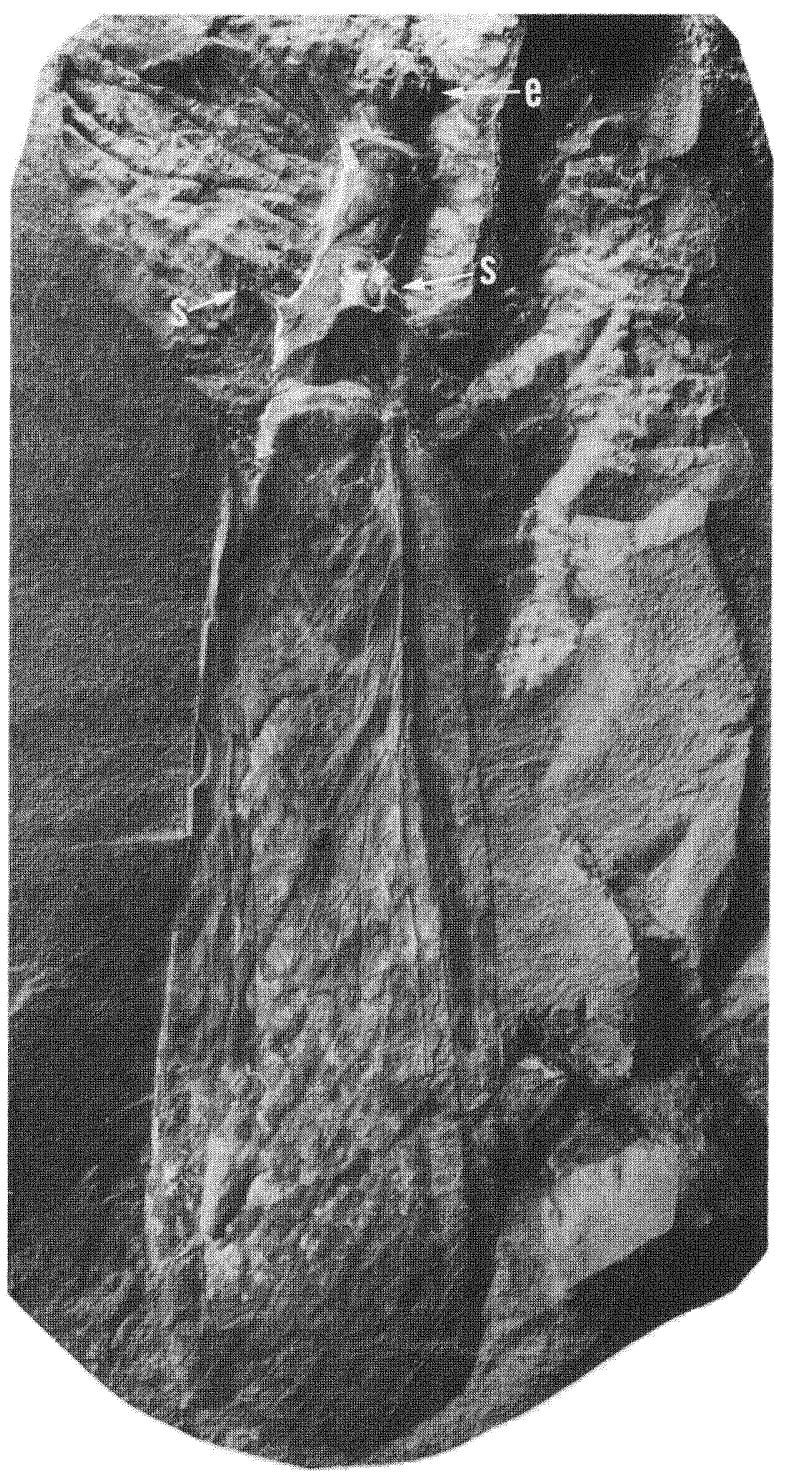

Fig. 5. Gerarus velus, photograph of specimen FMNH PE 32024. Note the narrow prothorax, and head, on which a compound eye is visible. Length of wing, 52 $\mathrm{mm}$. $\mathrm{e}=$ eye; $\mathrm{s}=$ spine. 
Holotype: USNM 38136. Specimen examined. This specimen consists of a prothorax, including spines, and the hindwings which overlap one another. Unfortunately, details of the venation are incomplete.

\section{Nen' material}

FMNH PE 32022. Obverse and reverse halves. The prothorax and five spines are preserved in this specimen but unfortunately, due to overlap, venational details are obscured.

FMNH PE 32024. Obverse and reverse halves. The head is well preserved, and complete with a compound eye, clypeus, one mandible, and a spine base. Parts of all three legs are also preserved. The enlarged prothoracic femur is probably an artifact of preservation, the result of lateral compression during burial.

DGLS 1. Obverse and reverse halves. This is a somewhat distorted specimen with the prothorax pushed into the mesothorax. Fore and hind wings on the right side are slightly splayed apart and reveal most of the venation of the hind wing.

Wolff 301 . Obverse and reverse halves. Only a fragmentary specimen with a poorly preserved prothorax and spine bases.

DMRW 2 (Dabasinskas 2). Obverse and reverse halves. An excellent specimen showing posterior part of the head, complete prothorax (although the spines are broken), mesothorax, metathorax, and wings, which unfortunately overlap. Its long and slender appearance and slim prothorax place it in this species.

\section{Gerarus danielsi}

Figures 2, 3, 6, 7, 8, 9, 10 and 11

Gerarus danielsi Handlirsch 1906a:147, 1906b:703, 1919:30.

Gerarus longus Handlirsch 1906a:147, 1906b:702, 1919:30. NEW SYNONYMY.

Gerarus angustus Handlirsch 1906a:148, 1906b:703, 1919:30. NEW SYNONYMY.

Gerarus latus Handlirsch 1911:313, 1919:30. NEW SYNONYMY.

Gerarus reductus Handlirsch 1911:314, 1919:30. NEW SYNONYMY.

Genoptery:x constricta Scudder 1885:327; Handlirsch 1906a:148, 1906b:704, 1919:30. NEW SYNONYMY.

Rossites inopinus Richardson 1956:44. NEW SYNONYMY.

\section{Description}

Fore wing: length $53-55 \mathrm{~mm}$, width $17-19 \mathrm{~mm}$; SC unbranched, parallel to $\mathrm{C}$, connecting to latter by multiple cross veins; $\mathrm{R}$ simple, parallel to SC, terminating at wing apex; RS pectinate with 2 to 3 
branches, originating from $R$ in basal third of the wing; CUP simple, originating from very base of $R$, connecting to RS by a short cross vein; $M$ four-branched, fusing for approximately $9 \mathrm{~mm}$ at its base with CUA; CUA also four-branched; CUP simple, arising independently of CUA at the wing base. CUP elbows towards CUA, connecting to it by short cross vein. Anal veins slender and bifurcating. Well-developed reticulation present in anal area.

Hind wing: length $40-48 \mathrm{~mm}$, width $14-16 \mathrm{~mm}$; SC and $R$ same as in fore wing; RS pectinate with five branches, arising from $\mathrm{R}$ near wing base; $M$ arising from near base of RS and deeply cleft with two or more terminal bifurcations; CUA and CUP parallel and independent at wing base. Anal area not well preserved, only slightly expanded, and with reticulated venation.

Prothorax: distinctly large and swollen posteriorly. There are nine prominent spines symmetrically arranged in the swollen region (see fig. 8). Width at widest point $10-13 \mathrm{~mm}$, length $20-22 \mathrm{~mm}$; spines 7-10 $\mathrm{mm}$ in length. One, possibly two, vertical spines extend from the anterior of prothorax, posterior to head.

Body: large, ranging from $70 \mathrm{~mm}$ to $75 \mathrm{~mm}$ (tip of wing to anterior tip of prothorax). Legs long and thin.

\section{Diagnosis}

This species may be distinguished from the other species in the genus by the large prothorax and well-developed spines (longer in this species than in any other); and the overall body size which is distinctly larger than that of either $G$. vetus or $G$. collaris from Mazon Creek. Although venational characters do vary intraspecifically, it should be noted that in the fore wing M connects to RS by a small cross vein, and that the anterior branch of CUP connects to CUA also by a small cross vein. This contrasts with the other species in the genus in which one finds an actual anastomosis of these veins.

Geological Range: Westphalian D. Occurrence: Mazon Creek, Illinois, U.S.A.

HOLOTYPE: USNM 35574. Specimen examined. Reverse half only. ${ }^{8}$ The bulbous region and spines of the prothorax are well preserved in this specimen. Only the costal margins of the fore wings are present, but venation of the hind wings is clear, except in the anal area. All evidence of the head and anterior region of the prothorax has been lost.

\footnotetext{
"The obverse half was originally in the Daniels collection, the location of which is not known (see Carpenter, 1965, for further details on this collection).
} 

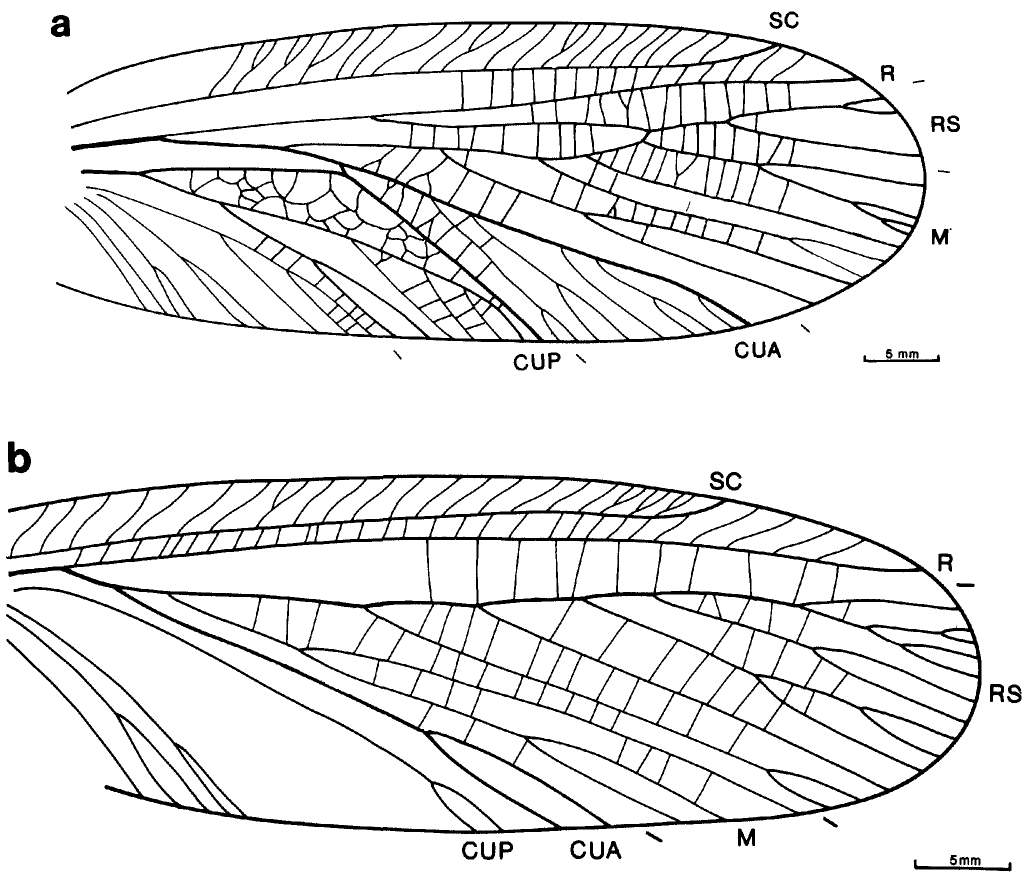

Fig. 6. Gerarus danielsi, a. composite drawing of the fore wing, based primarily on FMNH PE 5276, 31973; and DMRW 1. b. composite drawing of the hind wing, based primarily on USNM 35574, FMNH PE 32031, and MCZ 222.

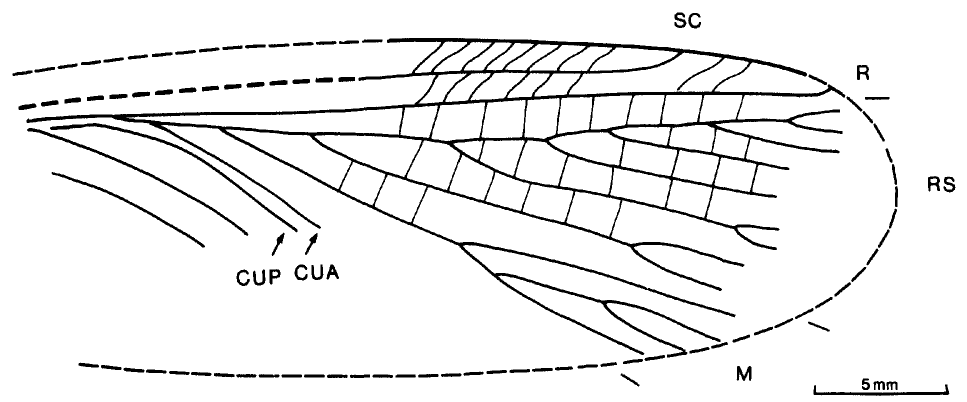

Fig. 7. Gerarus danielsi, originally Genopteryx constricta. Drawing of hind wing, based on USNM 38148. Compare this with the hind wing in Fig. $6 \mathrm{~b}$. 


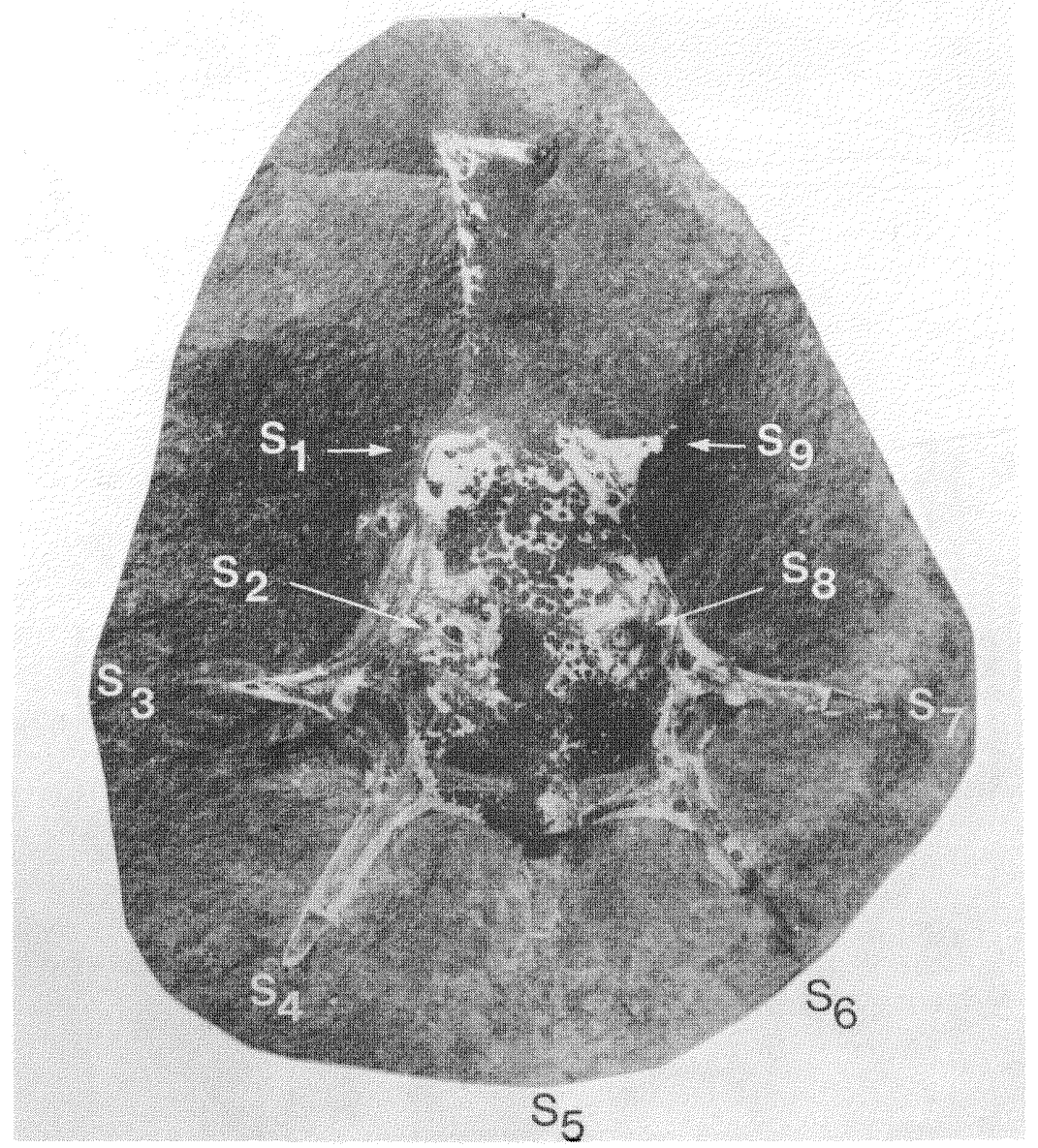

Fig. 8. Gerarus danielsi, photograph of the prothorax, PE 32029. Total length of prothorax, not including spines, $21 \mathrm{~mm}, \mathrm{~s}=$ spine.

\section{Synonymies}

Gerarus latus Y PM 33. Specimen examined. Obverse and reverse halves. This species is synonymized here with $G$. danielsi by virtue of its size (hind wing as preserved is $45 \mathrm{~mm}$ long, but is short several millimeters at its apex) and the shape of its prothorax. The latter, despite some distortion, clearly has spines of the same length and pattern as $G$. danielsi. A single spine base is present at the anterior 


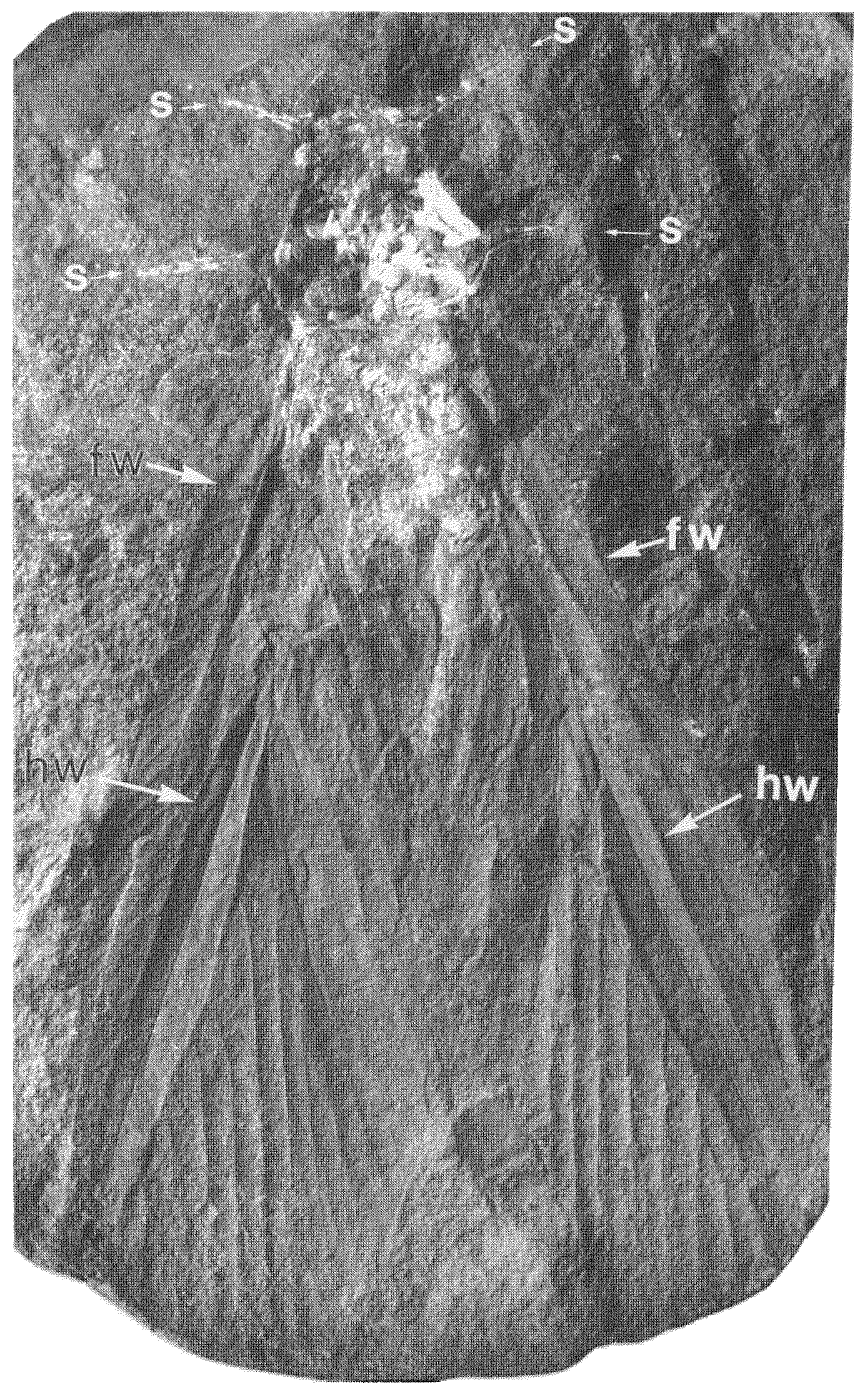

Fig. 9. Gerarus danielsi, photograph of the holotype, USNM 35574. Length of fore wing $42 \mathrm{~mm}$, as preserved. $\mathrm{fw}=$ fore wing; $\mathrm{hw}=$ hind wing; $\mathrm{s}=$ spine. 
tip of the prothorax. Fore and hind wings overlap. Only the costal area of the fore wing is visible, but most of the hind wing venation is visible under close scrutiny.

Gerarus reductus YPM 35. Specimen examined. Obverse and reverse halves. This is an unusual specimen in that two wings are preserved in the same concretion, but nothing suggests that they necessarily belong to the same specimen-or even to the same species. The specimen is badly fractured into four distinct pieces, and the two wings appear to be in different bedding planes. Handlirsch (1911) described the two wings as fore and hind wings of the same species, but expressed reservations concerning their generic assignment. I am convinced that these wings do not belong to the same specimen but believe instead that they are both hind wings belonging to different species. The specimen that Handlirsch (1911:315, fig. 20) considered to be a fore wing is here designated the lectotype of $G$. reductus and it is herein synonymized with $G$. danielsi. The specimen that he interpreted as the hind wing of $G$. reductus (1911:314, fig. 19) undoubtedly is a hind wing, but not sufficiently well preserved to warrant family determination and it is placed here in Protorthoptera incertae sedis.

Gerarus longus USNM 38822. Specimen examined. Obverse and reverse halves. Fore and hind wings overlap but the venation is very similar to that of the holotype of $G$. danielsi: RS is pectinate, with five branches, and $M$ is deeply cleft. Also the prothorax, although badly preserved, does have spines, two of which are visible on the left side. This, plus the size of the specimen (fore wing measures approximately $55 \mathrm{~mm}$, hind wing $44 \mathrm{~mm}$ ) warrants synonymy of $G$. longus with $G$. danielsi.

Gerarus angustus USNM 38811. Specimen examined. Obverse half only. This is a poor specimen: all four wings overlap, and the fossil has been weathered so the venation is only barely visible. Nevertheless, in my opinion, the overall size of the specimen (fore wing length is $55-57 \mathrm{~mm}$ ) and the swollen prothorax justify its synonymy with $G$. danielsi. Certainly it displays no unique characters by which it may be distinguished as a separate species.

Genopteryx constricta USNM 38148. Specimen examined. This species was originally assigned to the Geraridae by Scudder (1885), but later transferred by Richardson (1956) along with Rossites inopinus (see below) to the Caloneurodea. Having examined both 
type specimens, I find no characters by which to separate either genus from Gerarus. Because there are no significant differences in venation between $R$. inopinus, G. constricta and $G$. danielsi (compare fig. 6 with fig. 7), synonymy at this point seems justified.

Rossites inopinus FMNH PE 3304. Specimen examined. Obverse and reverse halves. Only the basal half of the hind wing is preserved, but it shows CUA and CUP very clearly. Length of the wing as preserved measures $29 \mathrm{~mm}$; actual length is estimated as $40 \mathrm{~mm}$.

\section{Nen' material}

FMNH PE 5276. Obverse and reverse halves. This specimen is, without doubt, the most spectacular of all specimens examined for this study. Both halves are excellent, and the obverse half gives a particularly good three-dimensional effect (see fig. 11). The latter also shows the entire prothorax and part of the head. The base of the vertical spine at the anterior end of the prothorax may be seen in the reverse half. Parts of all three legs are visible in the specimen and unequivocally demonstrate the gracile nature of the femora.

FMNH PE 31973. Obverse and reverse halves. An almost perfect specimen of a single $G$. danielsi fore wing. The apex of the wing is missing, but the anal area is remarkably well preserved in this specimen.

FMNH PE 31988. Obverse and reverse halves. This is a poor specimen: fore and hind wings overlap, and are only partially present. However, venation and size both place it in G. danielsi.

FMNH PE 32023. Obverse and reverse halves. This is not a wellpreserved specimen, but venation and size both conform to the species description.

FMNH PE 32027. Obverse half. The prothorax, pterothorax, and basal areas of the right hind wing and left fore wing are evident. The prothorax bears the characteristic arrangement of nine spines and also has a tiny lateral spine projecting from its anterior left side. Although smaller than the other specimens in this species (width of fore wing is $12 \mathrm{~mm}$ ) it is included in $G$. danielsi because it is, in all other respects, identical to the holotype.

FMNH PE 32029. Obverse and reverse halves. This specimen, which has an impressive array of spines on the prothorax, and a vertical spine at its anterior tip, is magnificent. Hind wings are preserved, but overlap. 


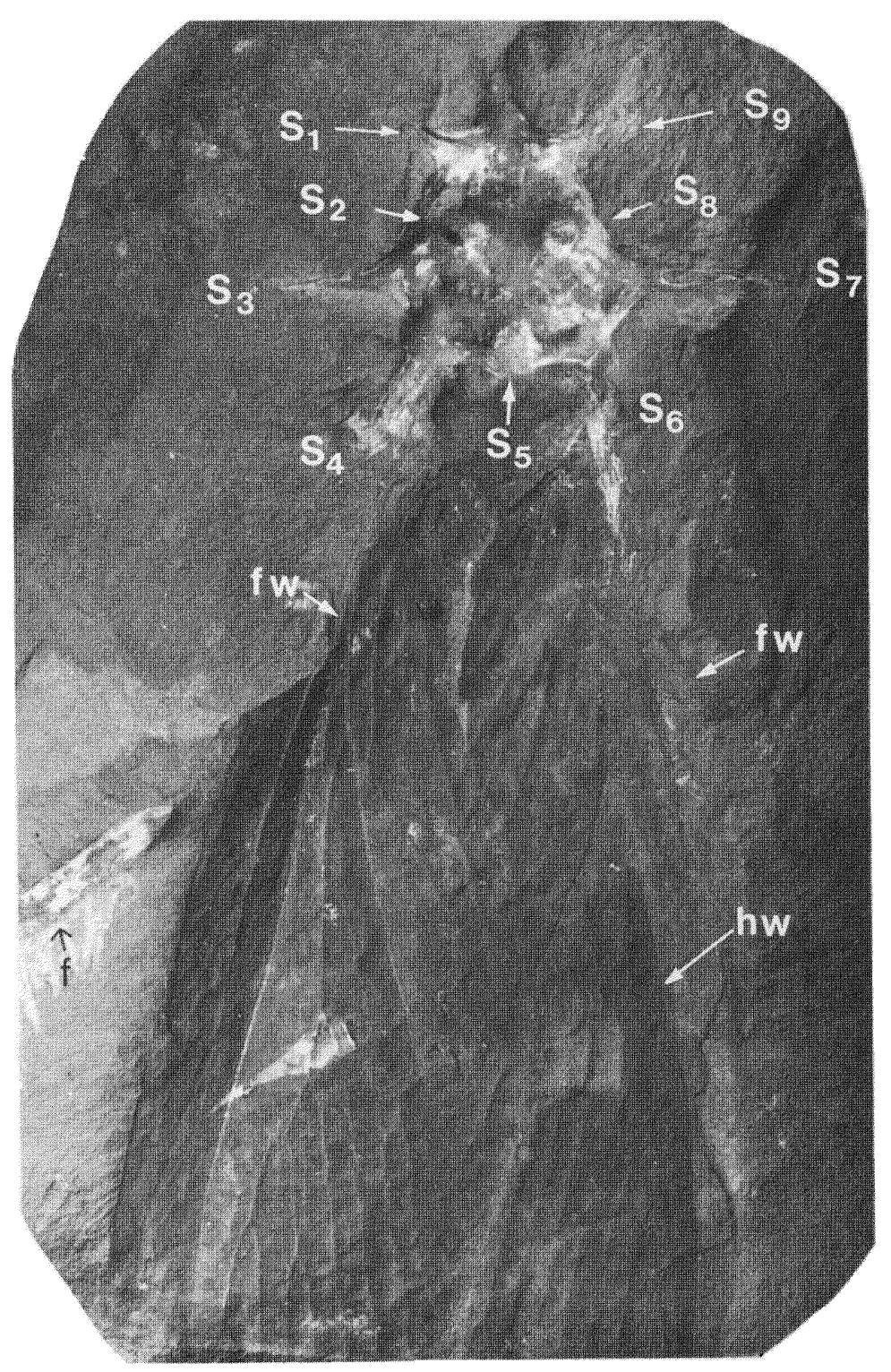

Fig. 10. Gerarus danielsi, photograph of FMNH PE 5276, obverse half. Length of fore wing $50 \mathrm{~mm}$, as preserved. $\mathrm{s}=$ spine; $\mathrm{fw}=$ fore wing; $\mathrm{hw}=$ hind wing. 


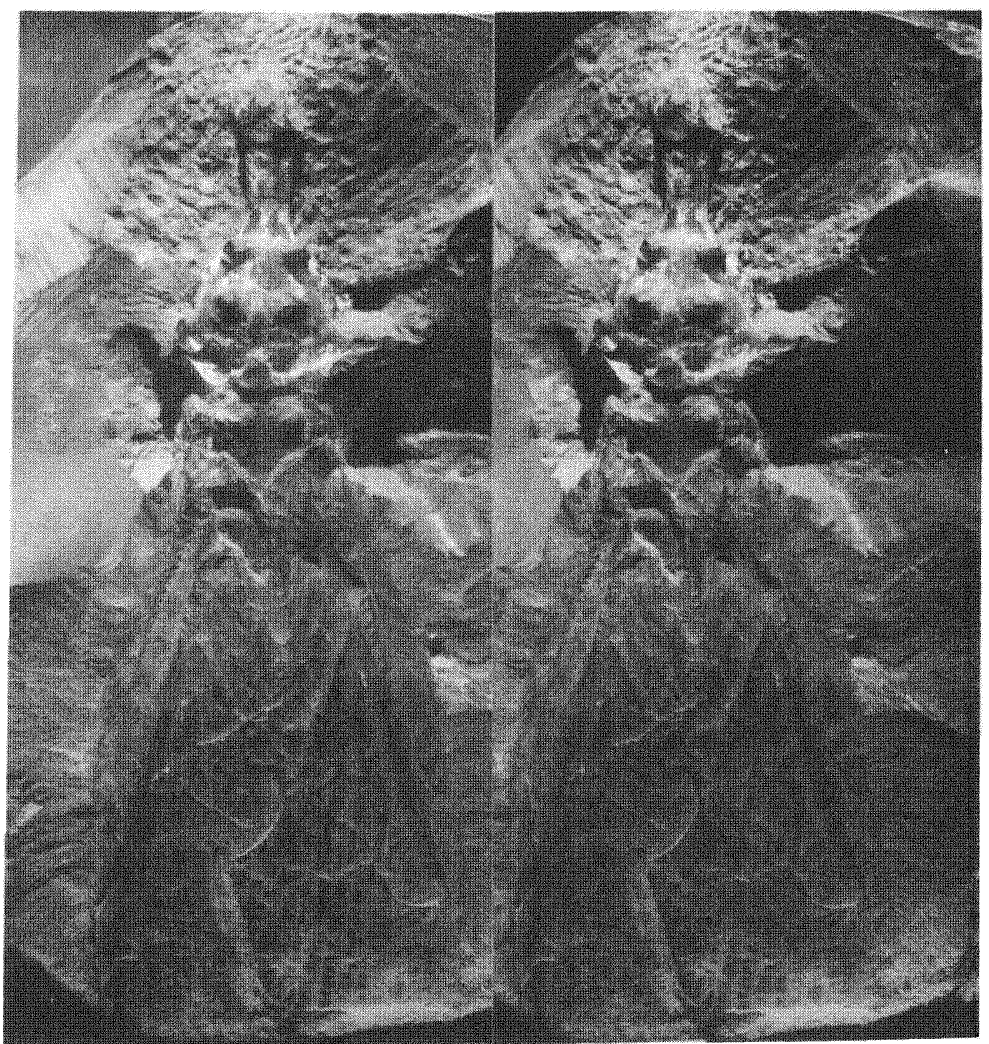

Fig. 11. Gerarus danielsi, stereophotograph of FMNH PE 5276, reverse half. Total length $=77 \mathrm{~mm}$. Photograph by F. M. Carpenter.

FMNH PE 32031. Obverse and reverse halves. This is an excellent specimen that shows the venation of the hind wing, and an outline of the prothorax, complete with spines.

DMRW 1 (Dabasinskas 1). Obverse and reverse halves. This is a beautifully preserved specimen, showing almost the entire fore wing, and two-thirds of the hind wing. It differs from the holotype in the nature of $\mathrm{M}$, which has only three major branches, but is otherwise consistent with $G$. danielsi. Recognition of DMRW 1 as a new species merely on the basis of $\mathrm{M}$, given that nothing is known of the body, does not seem warranted at this time. 
Wolff 491 . This specimen consists of head, thorax, and the basal area of two wings, but nothing can be made of the venation. The prothorax is large and bears at least seven spine bases. The head is preserved at a slight angle to the prothorax. Labrum is visible, as are one antenna and both eyes.

MCZ 222. Reverse half. Costal margin of the fore wings and most of the hind wings preserved. This insect is small for the species (hind wing measures $45 \mathrm{~mm}$ long, $14 \mathrm{~mm}$ wide) but the venation is indistinguishable from that of the holotype.

\section{Gerarus collaris}

Figures 12 and 13

Gerarus collaris Handlirsch 1911:314, 1919:30.

Gerarus longicollis Handlirsch 1911:315, 1919:30. NEW SYNONYMY.

\section{Description}

Fore wirg: length $45-50 \mathrm{~mm}$, width not known. Venation of fore wing obsr ured in all specimens.

Hind wing: length $40-45 \mathrm{~mm}$, width $10-12 \mathrm{~mm}$; RS apparently five-branched, $M$ deeply forked; CUA and CUP parallel.

Prothorax: small, $11 \mathrm{~mm}$ in length and narrow (approximately 6 $\mathrm{mm}$ wide). Posterior, or bulbous region, 7-8 $\mathrm{mm}$ long. Broken spines are present on all $G$. collaris specimens examined, but no more than six can be seen on any one specimen.

\section{Diagnosis}

This is the smallest of the Gerarus species. Unfortunately, the venation in all known specimens is not clear enough to serve as a species level character. G. collaris is, therefore, best recognized by its prothorax, which tapers gradually from the anterior to the posterior end, and is much narrower and shorter than in other species of Gerarus. The distinctive nature of the prothorax, and its usefulness as a species-specific character, can be seen by comparing figs. 5,11 and 13.

Geological Range: Westphalian D. Occurrence: Mazon Creek, Illinois, U.S.A.

HolotyPE: Gerarus collaris YPM 34. Specimen examined. Obverse half. Fore and hind wings overlap in this specimen, only the costal margin of the fore wing is well preserved. The prothorax is intact and several spine bases are visible, but the overall preservation is mediocre. 


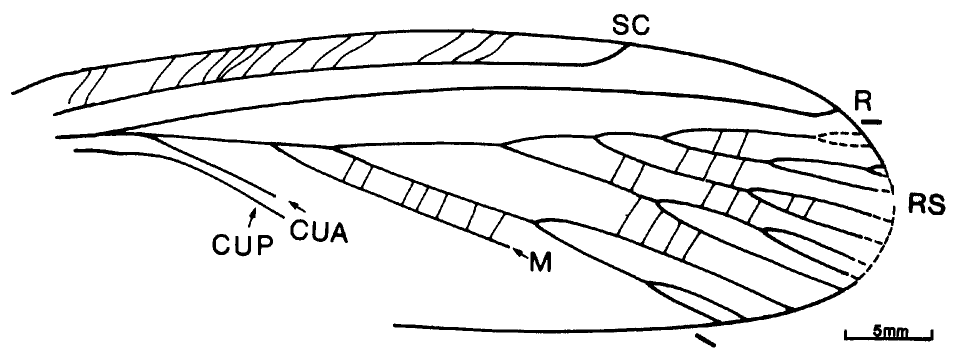

Fig. 12. Gerarus collaris, drawing of hind wing, based on holotype YPM 34.

Synonymy

G. longicollis YPM 36. Specimen examined. Obverse half. A fragmentary specimen. Wings are poorly preserved, and only RS and CUA/CUP in the hind wing are visible. This species is synonymized here with $G$. collaris on the basis of its prothorax, which is small and tapers gradually from the posterior to the anterior end, as it does in all known members of $G$. collaris.

\section{New Material}

USNM 38835. Obverse half. Only the base of the wings and the prothorax are preserved in this small specimen. The prothorax, which bears at least six spine bases, is clearly narrow and elongate, and is the reason for including this specimen in $G$. collaris.

\section{Gerarus fischeri}

Figures $14,15,16$ and 17

Sthenaropoda fischeri Brongniart 1885:59; Handlirsch 1906a:142, 1919:38.

Oedischia fischeri Brongniart 1894:559.

Sthenaropoda lerichei Lameere 1917:178. NEW SYNONYMY.

Sthenaropoda agnusi Lameere 1917:178. NEW SYNONYMY.

\section{Description}

Fore wing: length $40-50 \mathrm{~mm}$, width $14-15 \mathrm{~mm}$; SC parallel to C turning upward to fuse with it at point that is two-thirds length of wing; $\mathrm{R}$ parallel to $\mathrm{C}$, terminating at wing apex; both $\mathrm{SC}$ and $\mathrm{R}$ connecting to $\mathrm{C}$ and $\mathrm{SC}$ respectively by numerous sigmoidal cross veins; RS diverging from $R$ at midpoint of wing and branching twice; $M$ originating at base of $R$, anastomosing with $R S$ basally before branching off and forking once; CUP forked, originating 


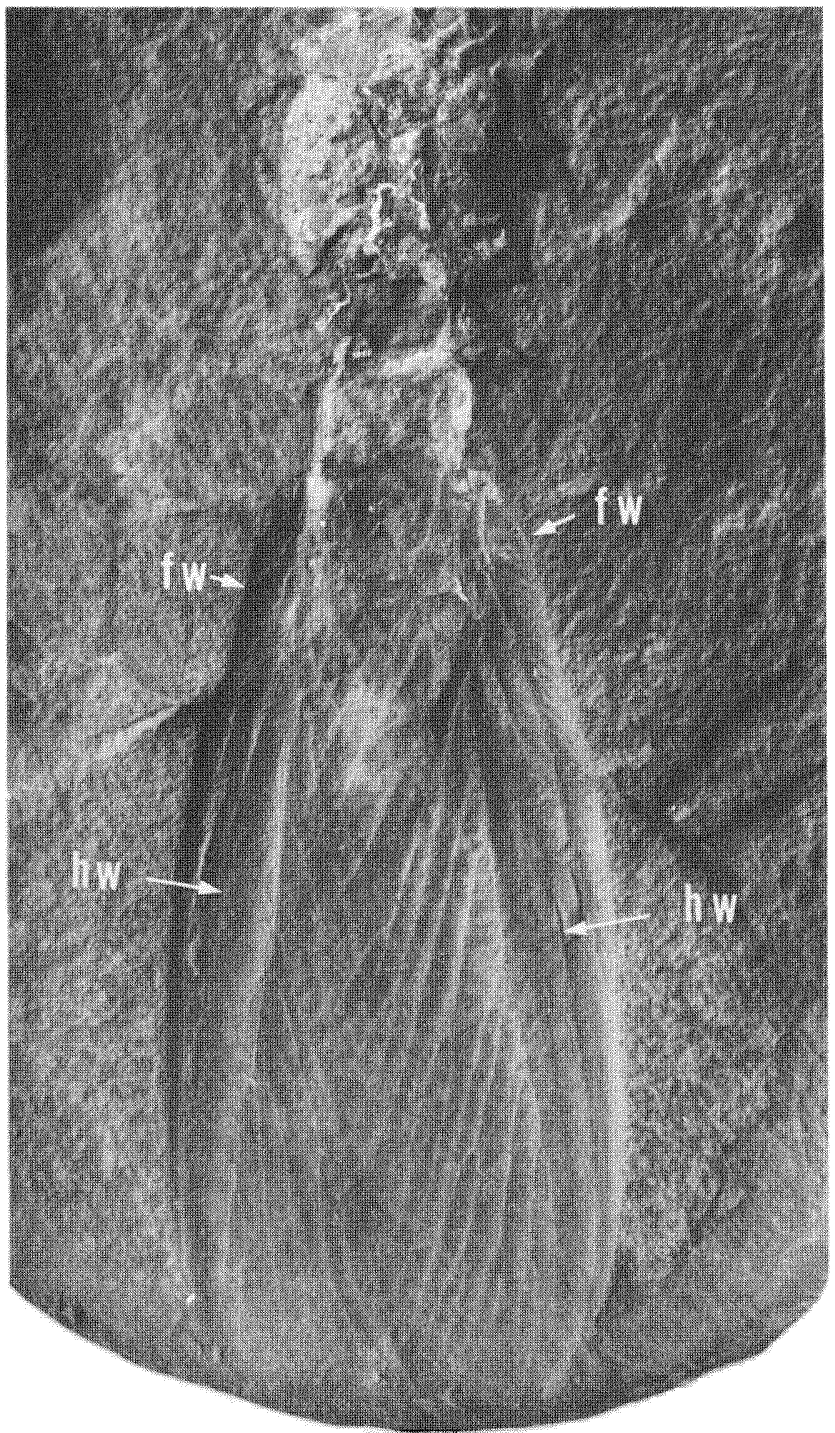

Fig. 13. Gerarus collaris, photograph of holotype, YPM 34. Length of fore wing $48 \mathrm{~mm} . \mathrm{fw}=$ fore wing; $\mathrm{hw}=$ hind wing . 
a

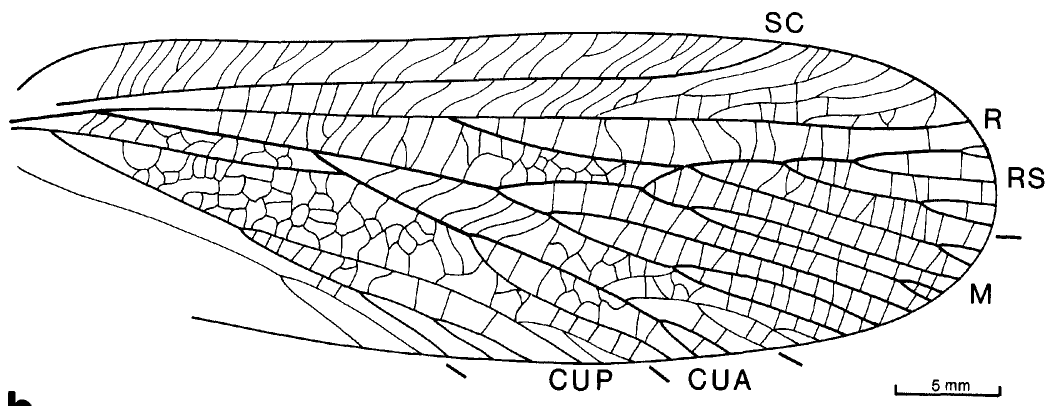

b

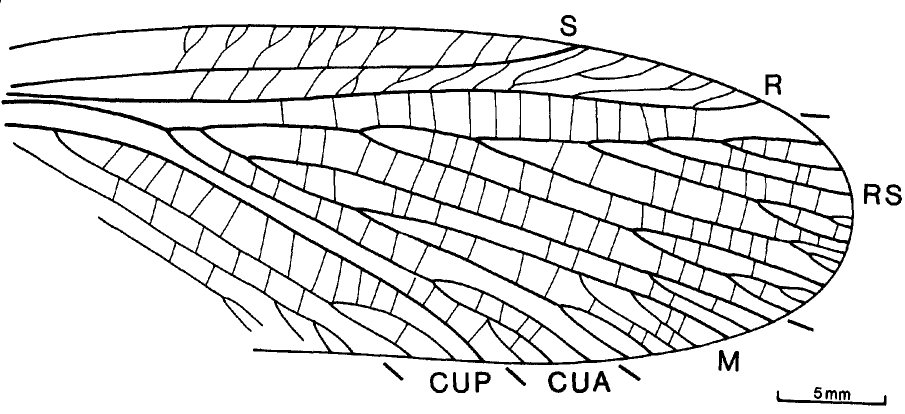

Fig. 14. Gerarus fischeri, a. drawing of fore wing, based on specimens IP 4, 5, 7, and 23. b. drawing of hind wing based on specimens IP 5, 7, and 10.

separately from CUA at wing base; anterior branch of CUP fusing with CUA for approximately $9 \mathrm{~mm}$ before weakly breaking away; multiple veins and well-developed reticulation present in anal area.

Hind wing: length $39-47 \mathrm{~mm}$, width $13-14 \mathrm{~mm}$; SC and R same as in fore wing; RS parallel to $\mathrm{R}$ and pectinate, with number of branches varying from four to five; spacing of these branches relative to one another also variable (in one specimen IP 2 the first branch of RS is connected to the main stem of RS by a strengthened cross vein, forming a small oval in the middle of the wing); $M$ deeply cleft with one or two branches; CUA and CUP parallel. The anal area of hind wing not known for this species, but appears to be slightly expanded, judging by overall wing shape. See fig. 17 . 


\section{Diagnosis}

G. fischeri is remarkably similar to $G$. danielsi in many respects: prothorax, size, venation (compare fore and hind wings of each in figs. 6 and 14). The only obvious difference lies in the nature of CUA and CUP in the fore wing. In fischeri CUA forks only once (in danielsi it has many small branches) and the anterior branch of CUP fuses with CUA for a distance of $9 \mathrm{~mm}$. In danielsi the two are connected by a small cross vein.

\section{Remarks}

G. fischeri was first described by Brongniart for a series of orthopteroid insects recovered from the Commentry Coal Basin. The series is remarkable not only because it contains a large number of individuals, but because most of these individuals are exceptionally well preserved. Under these circumstances it is somewhat odd that affinities between the Commentry species and the Mazon Creek species went unrecognized for so long. Many of the Commentry specimens (especially IP 5, IP 7, and IP 23) have most of the body, including the prothorax, preserved and demonstrate the same arrangement of spine bases seen in the Mazon Creek material. Moreover, venation of the fore and hind wings in these specimens is unequivocally clear. Handlirsch might have recognized the similarities between Sthenaropoda and Gerarus had he examined the Commentry material himself, but this is debatable since the fore wing for Gerarus was unknown at the time. The similarities between $G$. fischeri and $G$. danielsi, given above in the diagnosis, are extraordinary. While separation of the two species on such minor morphological differences might be subject to debate, I have chosen to recognize the two species as distinct from one another on geographical and geological grounds. G. danielsi comes from Mazon Creek in North America (Westphalian in age) and G. fischeri from Commentry in France (Stephanian in age).

Geological Range: Stephanian. Occurrence: Commentry, France.

HoLOTYPE: Gerarus fischeri. IP 5. Specimen examined. Obverse half only. This is probably the most spectacular of all the Commentry gerarids and of great taxonomic significance because the wings are splayed apart and venation of both fore and hind wings is readily visible. The insect is preserved dorso-laterally and the three legs 


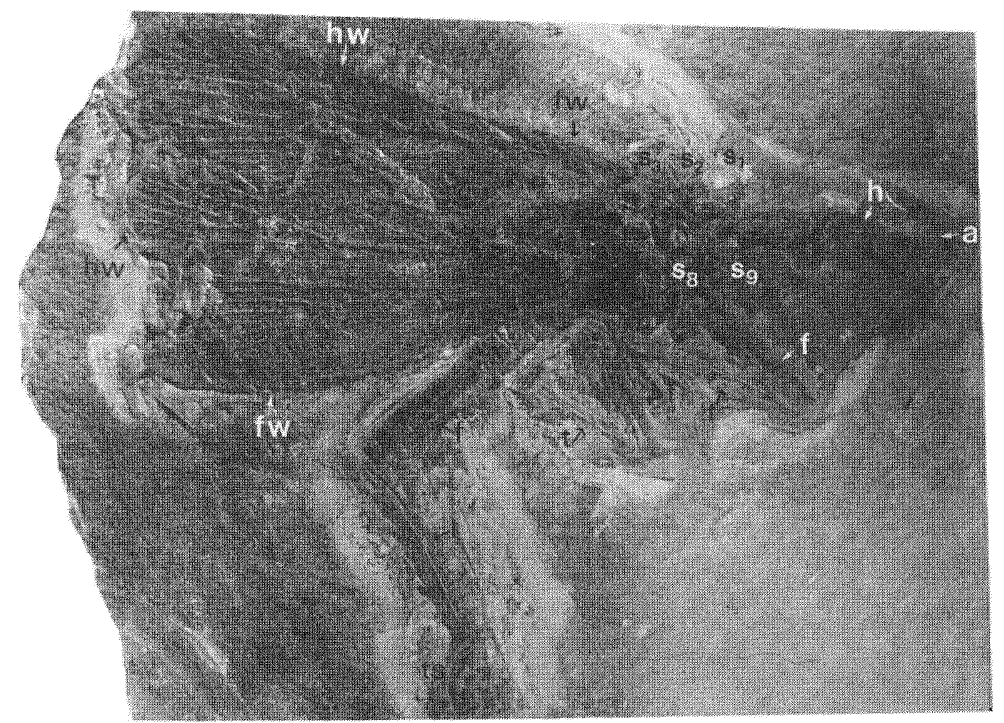

Fig. 15. Gerarus fischeri, photograph of holotype, IP 5. Total length $=75 \mathrm{~mm}$. $\mathrm{s}=$ spine; $\mathrm{h}=$ head; $\mathrm{a}=$ antenna, $\mathrm{f}=$ femur; $\mathrm{t}=$ tibia; $\mathrm{ts}=$ tarsomere; $\mathrm{fw}=$ fore wing; hw $=$ hind wing.

on the right side are preserved, as are the thorax and head. Spine bases are present on the bulbous region of the prothorax, although the spines themselves have broken off (see fig. 15).

\section{Synonymies}

S. lerichei. Holotype. IP 23. Specimen examined. Obverse half.

S. agnusi. Holotype. IP 19/21. Specimen examined. Obverse and reverse halves.

I am synonymizing these species with $G$. fischeri as there are no obvious specific level differences by which they may be recognized.

The specimen of $S$. lerichei is a well-preserved, dorsal compression of almost the entire insect. Because the wings are separated, it is possible to interpret the venation of both fore and hind wings, and especially that of the fore wing. The venation, the prothorax (including spine bases) and the size of this insect are perfectly compatible with $G$. fisheri.

The specimen of $S$. agnusi is a single fore wing, superbly preserved. Although the apex of the wing is missing, the basal area, 


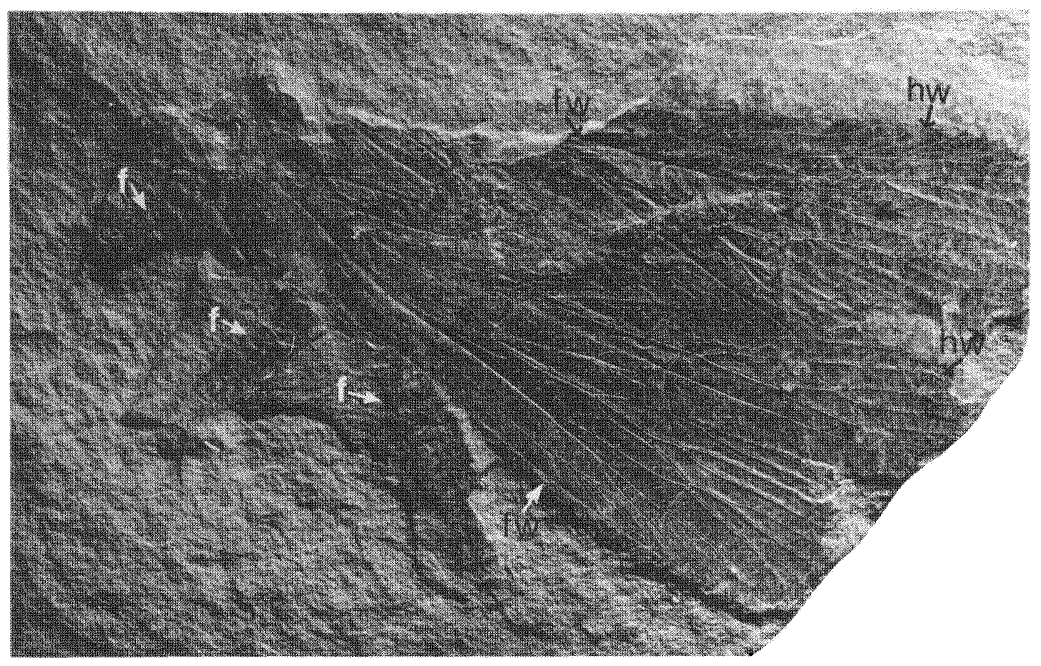

Fig. 16. Gerarus fischeri, photograph of IP 7. Length of fore wing $=50 \mathrm{~mm}$. $f=$ femur; $f w=$ fore wing; hw = hind wing.

including cross-veins, is extraordinarily well-preserved, as are all major veins. I cannot find sufficient differences between this specimen and the others already included in $S$. fischeri to warrant separate species status.

Several species previously included in Sthenaropoda are transferred here to family, genus indet. These are $S$. elegantissima Meunier and Sthenaropoda minor Handlirsch, the types of which I have examined, and I do not believe are similar enough to Gerarus to warrant inclusion in the family.

\section{New' Material}

IP 7. Reverse half. This specimen, although fragmentary, does show venation of fore and hind wings. The specimen is preserved dorso-laterally; three femora on the left side are visible, but the rest of the body including the thorax and head is missing. See fig. 16.

IP 8. Obverse half. This insect has both fore wings, a prothorax, complete with spine bases, a head bearing moniliform antennae, and 
parts of all six legs present. The hind femora are not enlarged and demonstrate unequivocally their cursorial nature.

IP 6. Reverse half. This specimen is not particularly well preserved due to apparent post-burial distortion of the insect. The pro- and mesothoracic legs on the left side are detached from the body, and the antennae, although present, are detached from the head. Fore and hind wings on the left side overlap, but the venation of the fore wing is preserved, and nothing of the hind wing. The prothorax is largely intact and shows the spine bases.

IP 4. Reverse half. The fore and hind wings on the left side are separated, and the venation of the left fore wing is clear. Unfortunately, little can be seen of the remaining three wings.

IP 2. Obverse half. A single well-preserved hind wing. Anal area is missing but may be folded under the wing. This wing differs from most other gerarid hind wings because the first branch of RS connects to the main stem of RS by a strengthened cross vein, forming a small triangle in the center of the wing (see fig. $17 \mathrm{c}$ ).

IP 3. Reverse half. This is a partially preserved insect and shows most of the right hind wing but only a fraction of the other three wings. It is interesting, however, for one feature: the right hind wing shows an anastomosis of the first branch of RS with the main stem of RS as seen in IP 2. Because the anastomosis in this specimen is smaller than in IP 2, and present in only one of the hind wings, it may be assumed that it is a form of intraspecific variation, and not significant at a higher level.

IP 9. Obverse half. Although the venation is virtually obscured, this specimen is important because the insect has been compressed laterally and all six legs are spread apart. The fore legs are only partially preserved, but the meso- and metathoracic legs on both sides are magnificent. This is the only specimen from Commentry in which one can count tarsal segments. There are five tarsomeres, and a pair of tarsal claws. The prothorax and its spine bases are also present in the fossil.

IP 10. Reverse half. This is a single hind wing and well preserved except at the apex and in the anal area, which is folded over.

IP 11. Reverse half. The specimen is a single hind wing, and so poorly preserved that the specimen is almost useless. 

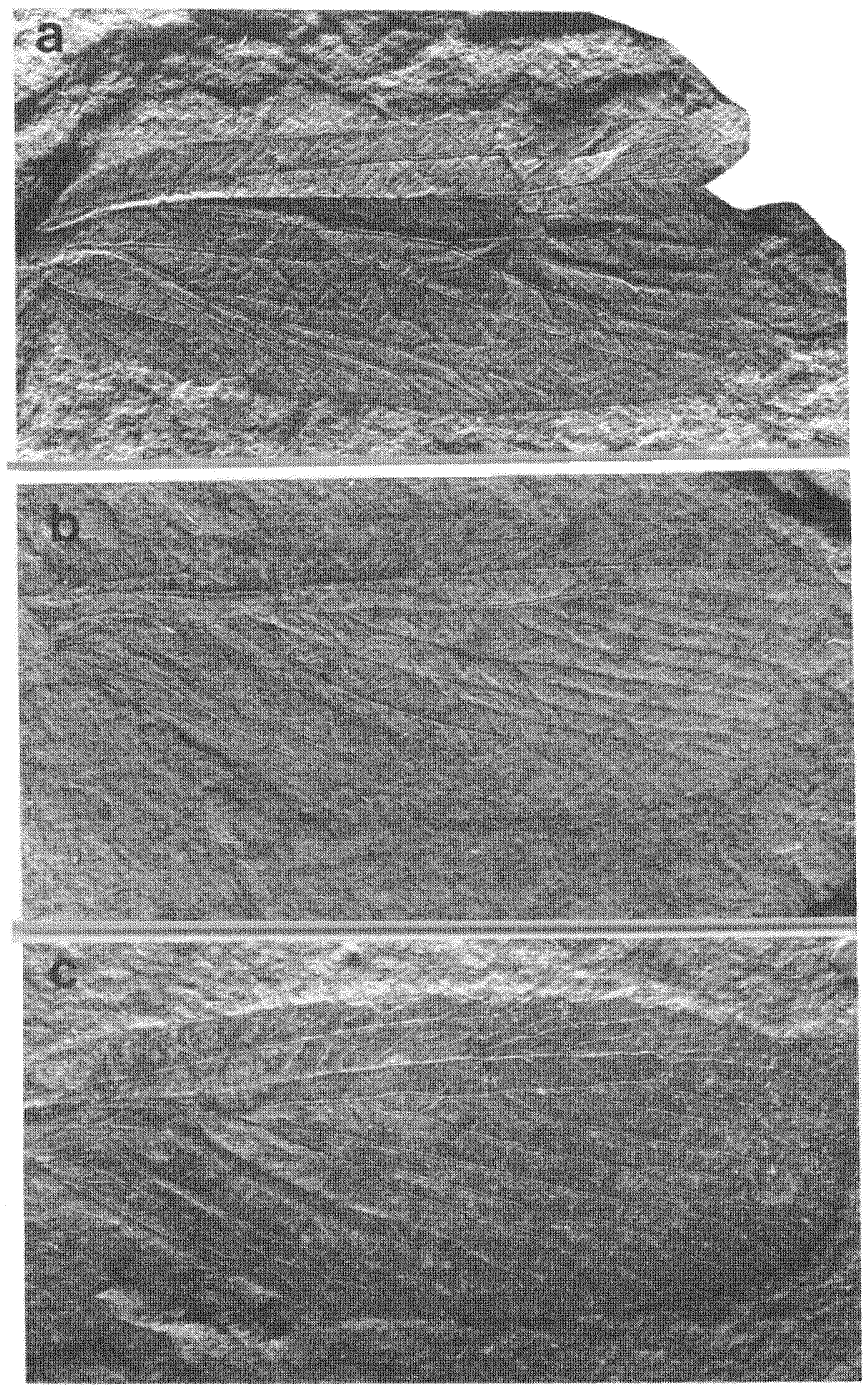

Fig. 17. Gerarus fischeri, a. photograph of fore wing, specimen IP 19. Length 42 $\mathrm{mm}$, as preserved. b. photograph of hind wing, specimen IP 10 . Length $40 \mathrm{~mm}$, as preserved. c. photograph of hind wing, specimen IP 2 . Length $40 \mathrm{~mm}$, as preserved. Note the small triangle formed by the anastomosis of one branch of RS with the main stem of RS. 
Gerarus bruesi

Figures 18 and 19

Archaeacridites bruesi Meunier 1909a:39.

Sthenaropoda bruesi Handlirsch 1919:39.

\section{Description}

Fore wing: length $45 \mathrm{~mm}$ (as preserved, estimated as $48 \mathrm{~mm}$ ), width $15 \mathrm{~mm}$; SC terminating in apical third of wing, at C; R parallel to $\mathrm{C}$, connecting to it apically by several cross veins; RS branching twice, each branch forking once distally; $M$ expanded, with five main branches; CUA four-branched, fusing with $M$ at its base; CUP elbowed towards CUA, connecting to the latter by a strong cross vein; anal veins present; well-developed reticulation present in area basal to CUA.

Hind wing: unknown.

\section{Diagnosis}

This species is based on a single, but almost perfectly preserved, fore wing from Commentry. Meunier originally described bruesi and assigned it to the genus Archaeacridites because he felt that this species was in some way ancestral to the extant Acrididae (order Orthoptera). While the relationships of the Protorthoptera (including the Geraridae) to the true Orthoptera have yet to be resolved, I do believe that synonymy of Archaeacridites with Gerarus is warranted. I have studied the holotype, and can find no characters to justify separate generic status for this species. However, I do think that species separation is warranted on the basis of CUA which connects to $\mathrm{M}$ only by a cross vein and does not anastomose with it as in $G$. fischeri. The nature of CUA in $G$. bruesi is much more reminiscent

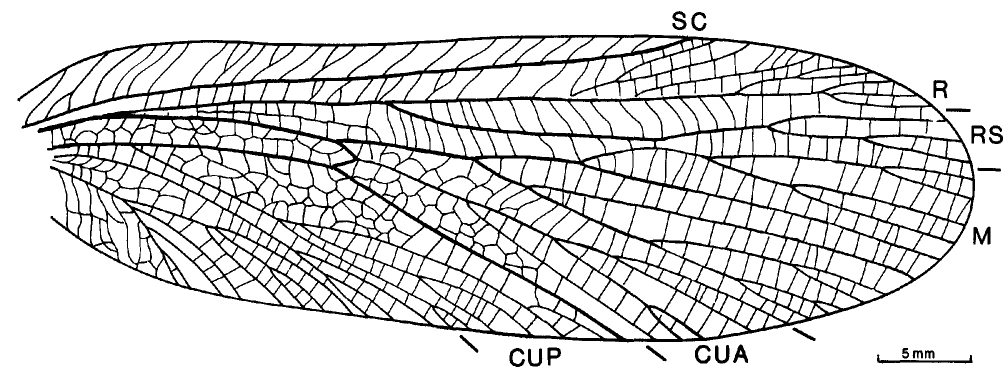

Fig. 18. Gerarus bruesi, drawing of fore wing, based on holotype no. IP 20. 
of $G$. danielsi, where CUA also connects with $\mathrm{M}$ by a short cross vein. $\mathrm{M}$, however, is more expanded (more branched) in G. bruesi than in G. danielsi.

Geological RANGe: Stephanian. OCcurrence: Commentry, France.

Holoty PE: Gerarus bruesi. IP 20. Specimen examined. This specimen is a single fore wing only, but beautifully preserved. All veins except those at the very apex of the wing are clear and can be interpreted without difficulty (see fig. 19).

\section{Genus Genentomum}

Genentomum Scudder 1885:329; Handlirsch 1906a:144, 1906 b:700.

\section{Description}

Fore wing: $\mathrm{SC}$ and $\mathrm{R}$ parallel to $\mathrm{C}$; $\mathrm{RS}$ branched, originating from $\mathrm{R}$ in basal third of wing; $\mathrm{M}$ distinctive with 3 to 4 branches, all parallel; CUA parallel to first branch of M; CUP elbowed towards CUA; anal area with several veins.

Hind wing: $\mathrm{SC}$ and $\mathrm{R}$ parallel to $\mathrm{C}$; RS multi-branched, arising from $\mathrm{R}$ near wing base; $\mathrm{M}, \mathrm{CUA}, \mathrm{CUP}$, and anal veins not known.

\section{Diagnosis}

This genus may be distinguished from the other genera in the family on the basis of $M$, which in the fore wing has the unique branching pattern described above, and the strong topography of the major longitudinal veins displayed by the two species assigned here to this genus.

Geological Range: Westphalian D. Occurrence: Mazon Creek, Illinois, U.S.A. TYPE SPECIES: Genentomum validum Scudder.

\section{Genentomum validum}

Figures 20 and 21

Genentomum validum Scudder 1885:329; Handlirsch 1906a:145, 1906b:700, 1919:40. Genentomum carri Cockerell 1917:81. NEW SYNONYMY.

\section{Description.}

Fore wing: length $45 \mathrm{~mm}$ (estimated), width $14 \mathrm{~mm}$; SC parallel to $\mathrm{C}$, connecting to it by a series of cross veins; costal margin narrow; $\mathrm{R}$ parallel to $\mathrm{C}$; $\mathrm{RS}$ at least two-branched, originating from $\mathrm{R}$ in basal third of wing; $M$ three-branched, and distinctive for the genus; CUA parallel to first branch of M; CUP elbowed towards CUA; anal area with several fine longitudinal veins. 


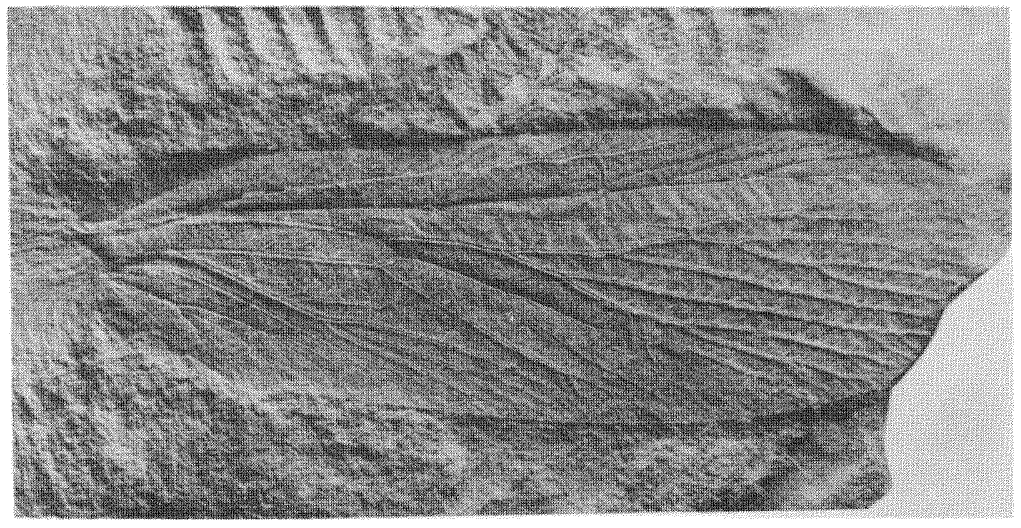

Fig. 19. Gerarus hruesi, photograph of holotype no. IP 20. Length of fore wing $45 \mathrm{~mm}$, as preserved.
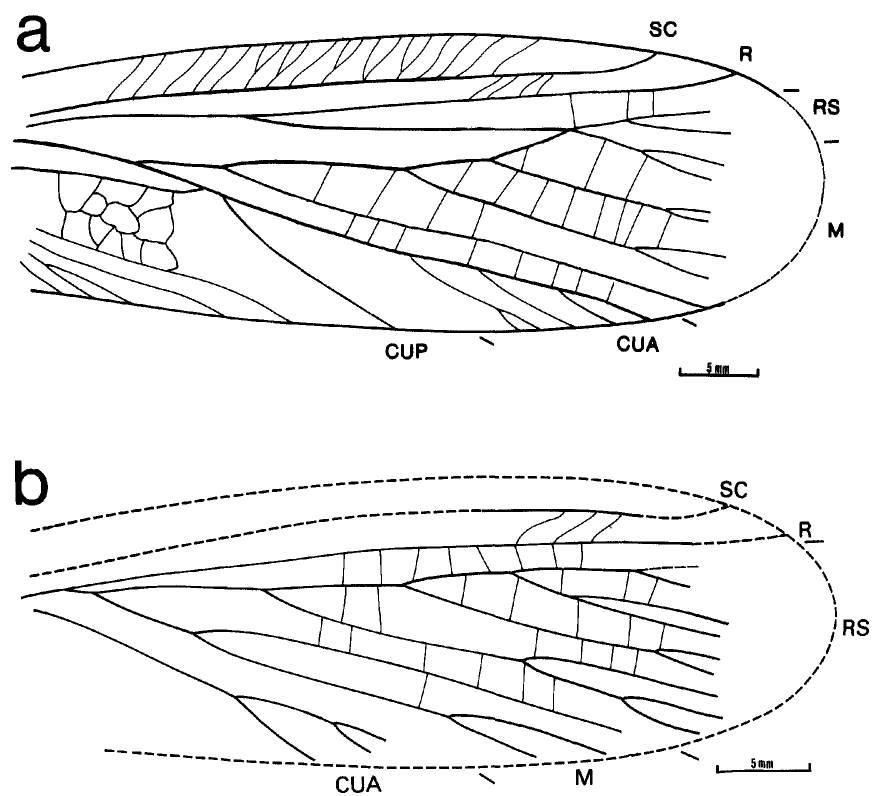

Fig. 20. Genentomum validum, drawings based on holotype no. USNM 38135. a. fore wing. $b$. hind wing. 

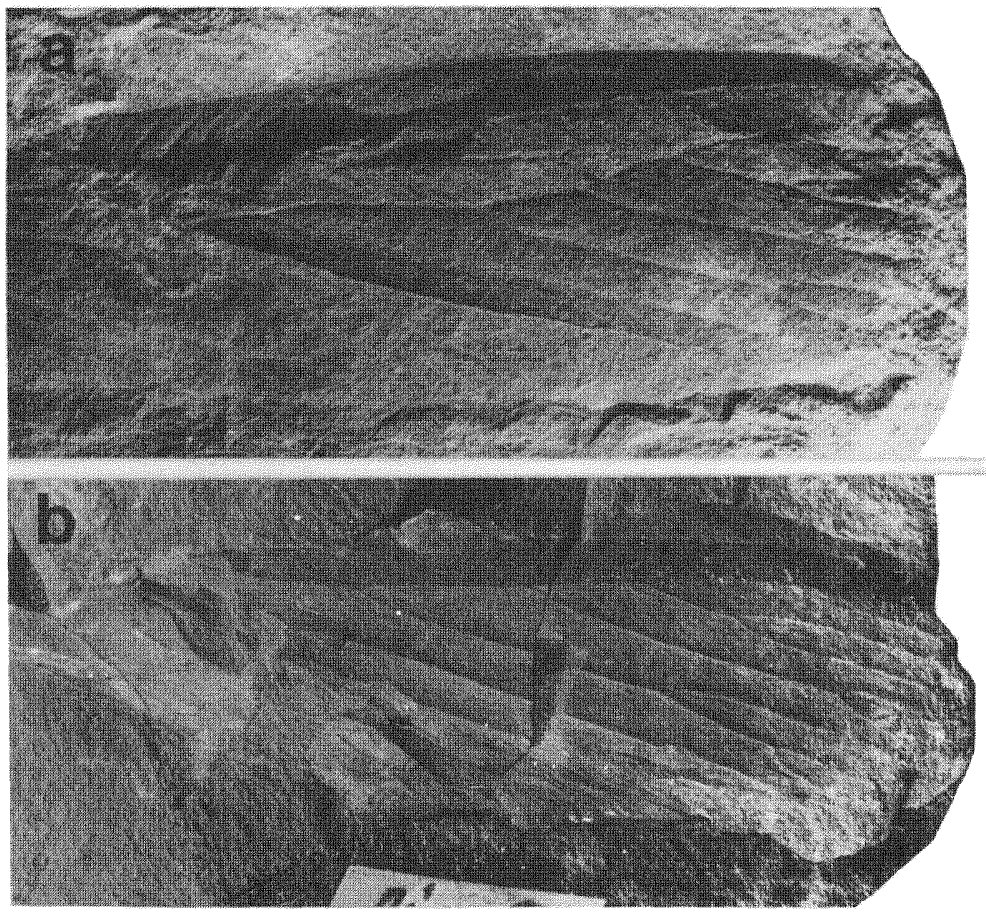

Fig. 21.Genentomum validum, photographs of holotype no. USNM 38135. a. fore wing. Length $42 \mathrm{~mm}$, as preserved. b. hind wing. Length $40 \mathrm{~mm}$, as preserved.

Hind wing: length $40 \mathrm{~mm}$, width $14 \mathrm{~mm}$; $\mathrm{SC}$ and $\mathrm{R}$ as in fore wing; $R S$ four-branched, originating from $R$ near wing base.

\section{Remarks}

Originally described by Scudder as a member of the Homothetidae (Neuroptera), this species was subsequently transferred to the family Oedischiidae by Handlirsch (1906b) on the basis of M, which anastomoses with RS in the fore wing. Of course Handlirsch had no idea that this character is also found throughout the Geraridae. My inclusion of Genentomum in the Geraridae is based on the study of all major veins and these are completely consistent for the family.

Geological Range: Westphalian D. Occurrence: Mazon Creek, Illinois, U.S.A.

HolOTYPE: USNM 38135. Specimen examined. Obverse and reverse halves. Both fore and hind wings are preserved, although the apex of the fore wing extended beyond the edge of the concretion 
and was therefore lost. Base and anal area of the hind wing also missing. Wings are separated and almost at right angles to one another.

\section{Synonymies}

Genentomum carri USNM 65023. Obverse half. This insect is an impression of the wings only. Although the wings do overlap, the fore wing on the right side and the hind wing on the left side are visible.

I am synonymizing Genentomum carri with Genentomum validum. Cockerell (1917) described this specimen as a new species on the basis of $\mathrm{R}$ which he figured with a single anterior branch. After close examination of the holotype, I find that he was incorrect in his interpretation of this vein as a branch of R. Either it is a very weak cross vein, or a wrinkle in the wing membrane. Branching pattern of $\mathrm{RS}$ in both fore and hind wings is similar to G. validum, and $\mathrm{M}$ is virtually identical in both.

The following genera and species are described from single specimens (most from single wings). Their descriptions are therefore somewhat approximate. There seems to be no justification for removing any of these taxa from the Geraridae at this point, although the discovery of more nearly complete specimens may provide characters that will alter this arrangement.

\section{Genus Progenentomum}

Progenentomum Handlirsch 1906a:145, 1906b:701, 1919:40.

\section{Description}

Fore wing: $\mathrm{SC}$ terminates in $\mathrm{C}$ at point two-thirds distance from wing base to apex; $\mathrm{R}$ parallel to anterior margin of wing, fusing with margin just before wing apex; RS pectinate with several branches; $M$ more branched than RS and elbowed distally, touching RS at that point; branches of RS and M close to one another and parallel; numerous cross veins present; CUA, CUP, and anal region not known.

Hind wing: unknown.

\section{Diagnosis}

Progenentomum is close to Gerarus but separated from it by RS, which has at least four branches in the fore wing. Compare with Genentomum. 
Geological Range: Westphalian D. Occurrence: Mazon Creek, Illinois, U.S.A. TYPE SPECIES: Progenentomum carbonis.

\section{Progenentomum carbonis}

Figures 22 and 23

Progenentomum carbonis Handlirsch 1906a:145, 1906b:701, 1919:40.

\section{Description}

Fore wing: length $30 \mathrm{~mm}$ preserved (estimated as $50 \mathrm{~mm}$ ), width $15 \mathrm{~mm}$; RS pectinate with four branches; distal branch of M elbows up to touch RS. A distinct cross vein connects branches two and three of $\mathbf{M}$, and probably acted as a brace vein.

\section{Diagnosis}

This species differs from all others in the family in having a linear series of punctations between R and RS. These may or may not have been pigmented, but because this specimen is only an impression, no organic material remains.

Geological Range: Westphalian D. Occurrence: Mazon Creek, Illinois, U.S.A.

HoLOTYPE: USNM 35580. Specimen examined. Obverse half.

\section{Genus Nacekomia}

Nacekomia Richardson 1956:33.

Description

Fore wing: $\mathrm{SC}$ terminates in $\mathbf{C}$ two-thirds from wing base; $\mathbf{R}$ parallel to SC; RS two-branched; $M$ four-branched; CUA and CUP simple.

Hind wing: unknown.

\section{Diagnosis}

Nacekomia differs from Gerarus only in the nature of $\mathrm{M}$, which is separate from RS, and not connected to it except by several very small cross veins. This, in my opinion, warrants separate generic status but not separate family status.

\section{Remarks}

This monotypic genus was originally included in the family Cacurgidae (order Protorthoptera), but is here transferred to the Geraridae on the basis of its fore wing venation. While one cannot 


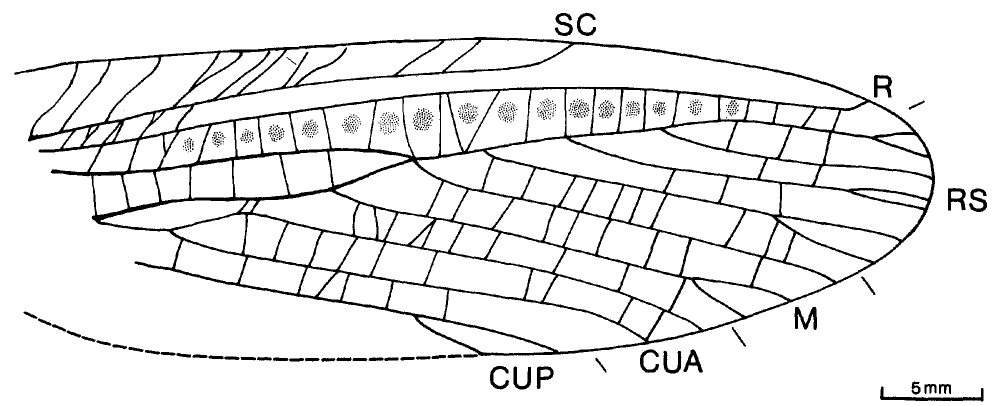

Fig. 22. Progenentomum carbonis, drawing of fore wing based on holotype no. USNM 35580.

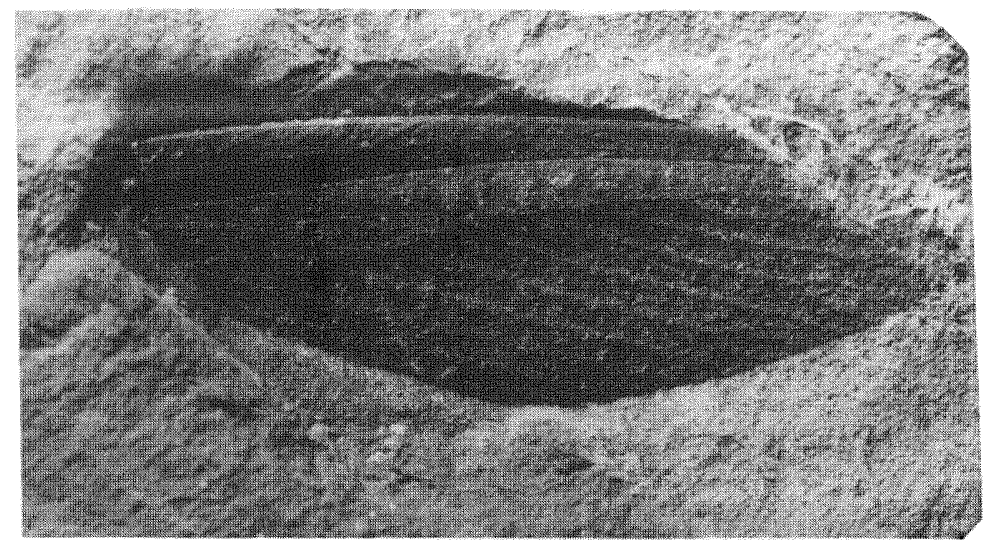

Fig. 23. Progenentomum carbonis, photograph of fore wing, based on holotype no. USNM 35580 . Length $30 \mathrm{~mm}$, as preserved.

be certain that this genus belongs in the Geraridae until a more nearly complete specimen is found, the fore wing is so similar to that of Gerarus that I do not hesitate to include it in the family. I certainly can see no justification for the inclusion of Nacekomia in the Cacurgidae, where it was placed by Richardson (1956). The venation of Nacekomia differs considerably from that of Cacurgus. In the latter, $R$ is branched, RS simple, $M$ is reduced, CUA simple, and CUP many branched. In the former, $R$ is simple, $R S$ branched, $M$ has many branches, and CUA and CUP are simple.

Geological Range: Westphalian D. Occurrence: Mazon Creek, Illinois, U.S.A. TYPE SPECIES: Nacekomia rossae. 
Figures 24 and 25

Nacekomia rossae Richardson 1956:34.

\section{Description}

Fore wing: length $43 \mathrm{~mm}$, but apex is missing; SC terminates in C, two-thirds distance from wing base; $\mathrm{R}$ parallel to $\mathrm{SC}$, terminating at wing apex; RS two-branched, diverging from $R$ at midpoint of wing; $M$ with four well-developed branches; CUA strongly convex and fused at base with $M$, nature of CUP uncertain.

Hind wing: unknown.

\section{Diagnosis}

It is impossible to designate specific characters when the genus is based on a single specimen, but in all probability the nature of RS (with only two branches) may be important.

Geological Range: Westphalian D. OcCurrence: Mazon Creek, Illinois, U.S.A.

HolotyPE: Nacekomia rossae FMNH PE 791. Specimen examined. Obverse half.

\section{Genus Gerarulus}

Gerarulus Handlirsch 1911:318, 1919:30.

\section{Description}

Fore wing: SC parallel to $\mathrm{C}$, terminating on it; $\mathrm{R}$ simple, RS branched; $M$ with multiple branches, anastomosing briefly with RS; CUA simple, CUP elbows towards CUA.

Hind wing: SC and R same as fore wing; RS pectinate; $M$ simple; CUA and CUP independent from one another and parallel.

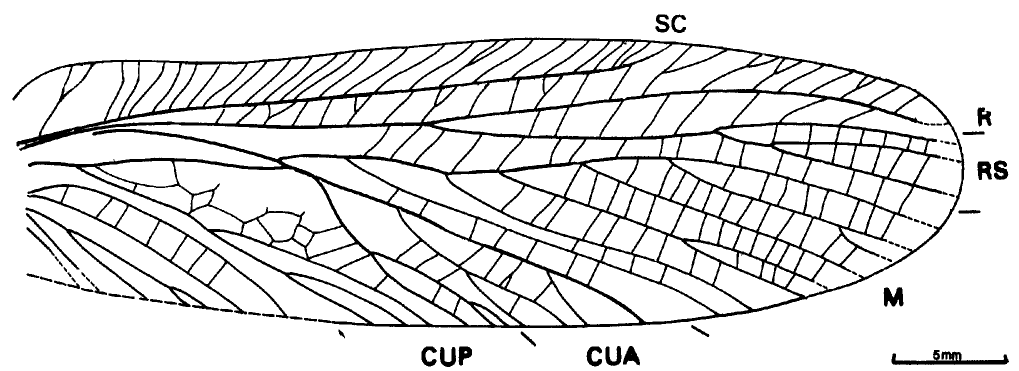

Fig. 24. Nacekomia rossae, drawing of fore wing based on holotype no. FMNH PE 791. 


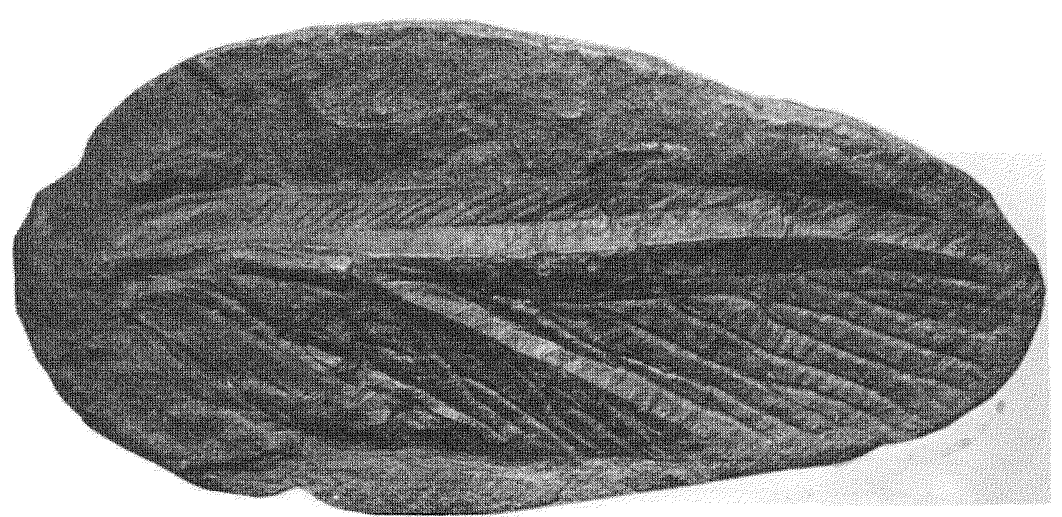

Fig. 25. Nacekomia rossae, photograph of fore wing of holotype no. FMNH PE 791. Length $43 \mathrm{~mm}$.

\section{Diagnosis}

Although the prothorax is unknown, venation of fore and hind wings is typical for the family. I have retained this as a distinct genus only on the basis of the diminutive size of its one species, and this may change as more material is found.

Geological RANGE: Westphalian D. Occurrence: Mazon Creek, Illinois, U.S.A. TYPE SPECIES: Gerarulus radialis.

\section{Gerarulus radialis}

Figures 26 and 27

Gerarulus radialis Handlirsch 1911:316, 1919:30.

\section{Description}

Fore wing: length $25 \mathrm{~mm}$ as preserved (estimated as $35 \mathrm{~mm}$ ), width $11 \mathrm{~mm}$; SC parallel to $\mathrm{C}$, terminating on it; R simple, RS branched (at least two or three times); $\mathrm{M}$ anastomosing briefly with RS, appearing to be four-branched; CUA simple, CUP elbowed towards CUA; two anal veins visible, each forking once.

Hind wing: length $21 \mathrm{~mm}$ as preserved (estimated as $30 \mathrm{~mm}$ ), width $10 \mathrm{~mm}$; $\mathrm{SC}$ and $\mathrm{R}$ simple and parallel to C; RS pectinate, although the number of branches is unknown; CUA and CUP independent from one another and parallel; anal area slightly enlarged; abdomen, although indistinctly preserved, appears to be rather slender; prothorax missing. 
a
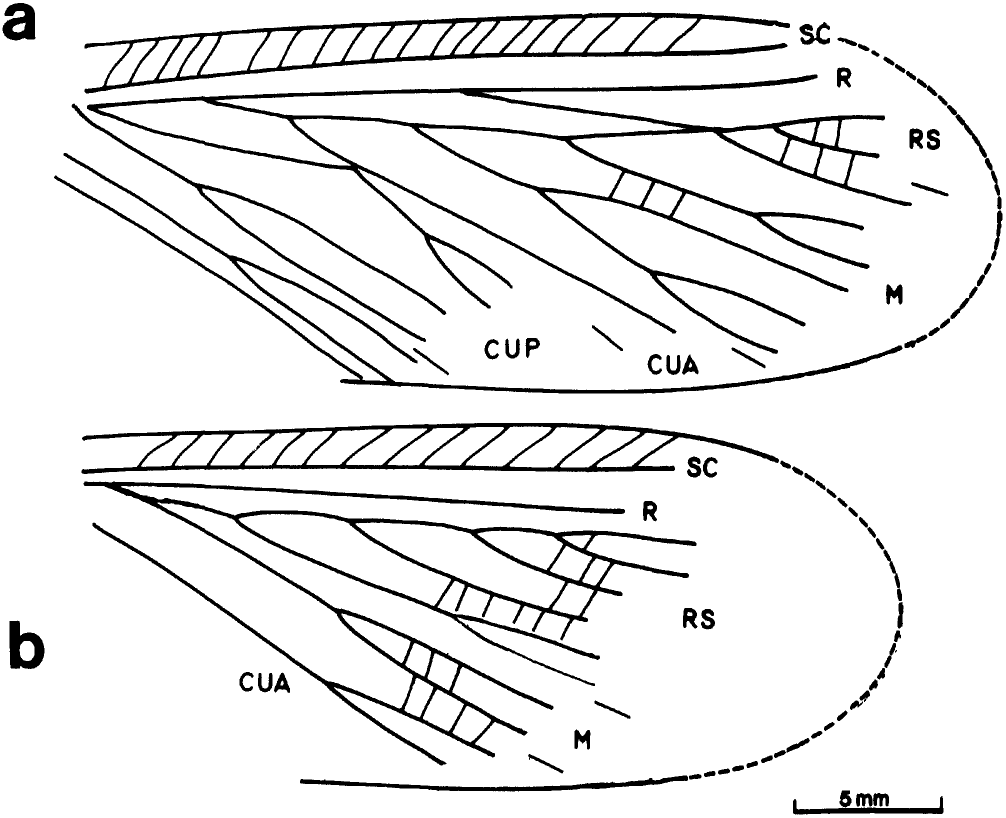

Fig. 26. Gerarulus radialis, drawings based on holotype no. YPM 37. a. fore wing. b. hind wing.

\section{Diagnosis}

This is the smallest of all the gerarids and its size seems, at present, to be the most distinguishing feature of this species.

Geological range: Westphalian D. Occurrence: Mazon Creek, Illinois, U.S.A.

HolOTYPE: YPM 37. Specimen examined. Obverse and reverse halves. This specimen is somewhat unusual in that both fore and hind wings are stretched out on one side of the body and do not overlap at all. The abdomen appears to be rather slender. The prothorax is missing.

\section{Genus Anepitedius}

Anepitedius Handlirsch 1911:318, 1919:30.

\section{Description}

Owing to the poor state of preservation of the type specimen, it is impossible to describe diagnostic characters for this genus. 


\section{Remarks}

It is clear that this genus belongs in the family Geraridae: the prothorax is distinctively shaped, and the limited venational characters are in accordance with the family. Unfortunately, since this is a monotypic genus and based on a single, poorly preserved specimen, it is impossible to assess its relationship to other taxa in the family.

Geological range: Westphalian D. Occurrence: Mazon Creek, Illinois, U.S.A. TYPE SPECIES: Anepitedius giraffa.

\section{Anepitedius giraffa}

Anepitedius giraffa Handlirsch 1911:318, 1919:30.

\section{Description}

Fore wing: length $40 \mathrm{~mm}$, width $10 \mathrm{~mm}$; $M$ converges with RS, connecting to it by a short cross vein before diverging.

Hind wing: apical half of wing missing and only costal margin visible.

\section{Remarks}

This species deviates from the other species in the family by having a combination of narrow wings and a robust prothorax. Unfor-

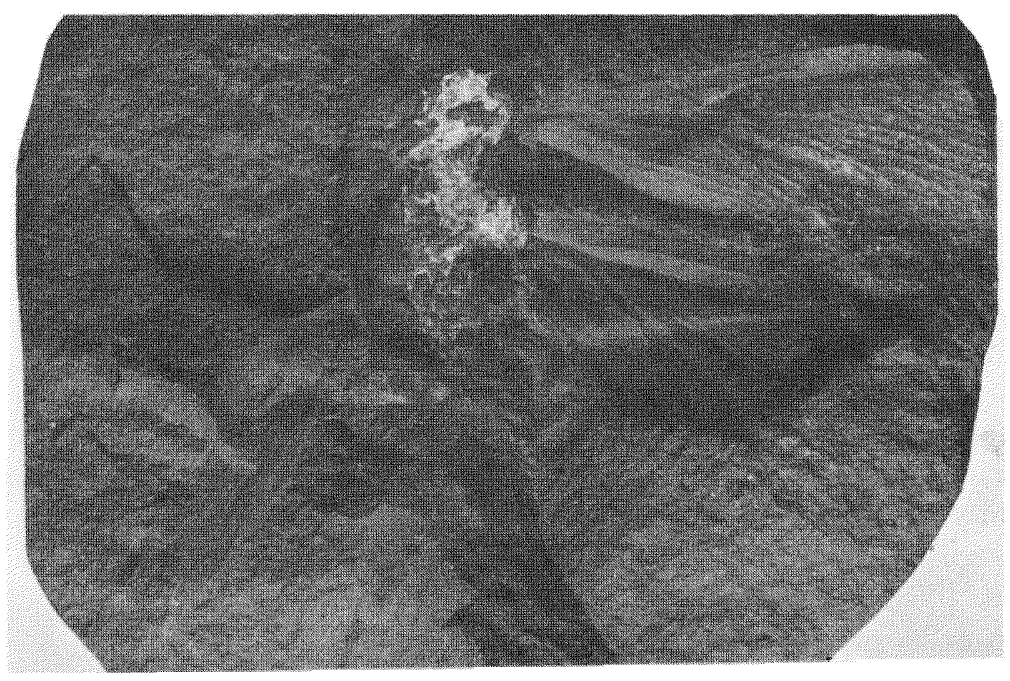

Fig. 27. Gerarulus radialis, photograph of holotype no. YPM 37. Length of fore wing $25 \mathrm{~mm}$, as preserved. 
tunately, the poor preservation of the one specimen known precludes a more detailed species description.

Geological Range: Westphalian D. Occurrence: Mazon Creek, Illinois, U.S.A.

HolOTYPE: YPM 38. Specimen examined. Obverse and reverse halves.

\section{Depositional EnVironment}

For most of this century, Mazon Creek and Commentry have reigned as the two major localities of Upper Carboniferous insects (a third locality has just been added to this list; see Burnham, 1981). Both have provided large numbers of superbly preserved specimens and have contributed greatly to our understanding of early insect evolution. Because the family under consideration is represented at both places, a comparison of their geological history is warranted.

Roughly three hundred million years ago, in the Stephanian Stage of the Upper Carboniferous, the Commentry Coal Basin was a shallow lake- $-9.6 \mathrm{~km}$ long, $3.2 \mathrm{~km}$ wide, and encircled by mountains (Fayol, 1887; Stevenson, 1909). Two principal streams descended from the surrounding mountains into the lake, where deltaic swamps formed from the deposition of fine-grained sediments. These were, in many respects, typical coal swamps, characterized by Cordaites, and, in lesser numbers, other coal swamp flora such as Lepidodendron and Stigmaria. Fossilization at the site was almost instantaneous, the result of flooding that deposited massive amounts of sediment in the lake and bordering swamp. The remarkable preservation of the Commentry insects would not have been possible without their immediate burial under these catastrophic conditions, and it is assumed that they were buried with minimal post-mortem transportation.

The first fossils at Commentry were discovered in the midnineteenth century as a result of extensive coal exploration in the central region of France, and were made accessible to collectors only because of intense mining activity in the area. Once the coal supply began to diminish, about 1915 , the mines were closed down and filled in, and further fossil collecting prohibited. For an historical account of the Commentry collections and a review of the literature on Commentry insects, see Carpenter (1943). 
Mazon Creek, in contrast, was once part of a major delta on the edge of the Illinois Basin Sea. Periodic floodings in this area resulted in the burial and preservation of a wide diversity of organisms, both plant and animal. Two assemblages are recognized: the Essex fauna (mostly marine organisms); and the Braidwood assemblage (freshwater to brackish flora and fauna). According to Richardson (1956:11-12) the Braidwood fossils "represent the fauna that lived on an aggrading plain, [just] above sea-level" and consisted of "more than 200 species of small animals, including insects, arachnids, mussels, and amphibians." Over 140 species of insects have so far been described from this locality (Richardson, pers. comm.) and many of the specimens show exceptionally fine detail.

Unlike the Commentry fossils, which are preserved in shale, Mazon Creek fossils are found primarily in iron carbonate or siderite concretions. These concretions (also called nodules) form due to decay of the organism contained within them, but will do so only under the right conditions (iron-rich sediments, high $\mathrm{pH}$, rapid burial). They are characteristic of certain Upper Carboniferous coalbearing strata and have been recorded from localities in the United States, France, England, and Germany. Nodules are shaped roughly according to the dimensions of the organism they contain and can be split along the bedding plane to reveal their fossilized contents. Preservation is generally good, although appendages (particularly legs) are frequently lost due to insufficient chemical reaction in the extremities. For a more detailed account of concretion formation see Woodland and Stenstrom (1979).

The Mazon Creek biota has been known since the middle of the nineteenth century (Nitecki, 1979), but their initial discovery (unlike Commentry) was due to the erosion of fossil-bearing strata by stream action rather than by mining exploration. Concretions washed out by the stream (Mazon Creek) accumulated along its banks, and were found there by local collectors. Eventually the area became the focus of extensive mining exploration and several pit mines were dug in an effort to obtain coal. This was enormously beneficial to paleontologists because it exposed great numbers of concretions that then became available for study. Although most of the mining has now ceased, at least one mine remains open (pit eleven) from which fossils are still being collected, primarily by an 
avid corps of amateur collectors, many of whom have made their finds available for scientific study.

The presence of the Geraridae at both Mazon Creek and at Commentry may seem somewhat surprising. ${ }^{9}$ The Mazon Creek locality is roughly 5 to 10 million years older than that at Commentry and the two formed under quite different circumstances. How can the presence of Gerarus at both be explained?

To find an answer, one must look at land mass movements during the Carboniferous, and at their influence on climatic patterns and continental distributions (see fig. 28). The collision of the continents Gondwana and Laurasia during this period had two major consequences. These were 1) the formation of the Allegheny Mountain range in North America; and 2) the alignment of eastern North America and western Europe so that they were contiguous at zero latititude. The significance of these events for the family Geraridae is twofold. One, the separate land masses were fused into a single continent, and two, their new position along the equator resulted in the formation of extensive coal swamps throughout North America and Europe. These events made dispersal of insects from one region to the other relatively easy. Although the creation of the Allegheny Mountain chain may have acted as a barrier to dispersal for some insects (and other animal and plant species), this was probably not so for those that were strong fliers. It is likely, therefore, that the Geraridae were able to cross the barrier, and in so doing, passed from one coal swamp habitat to another. It is assumed, being orthopteroids, that they were herbivores, and probably restricted in their feeding habits to plants found in these swamps. It is not surprising, then, that they should have been so widespread and successful during the Upper Carboniferous. For the same reason, it is not surprising that they died out by the end of the Carboniferous when climatic changes led to the drying up of the great coal swamps and the concomitant extinction of the coal swamp fauna and flora.

\footnotetext{
${ }^{4}$ Three other genera common to both these localities have previously been reported. They are Homaloneura (Carpenter, 1964) and Spilaptera (Carpenter and Richardson, 1971) in the order Paleodictyoptera, and Mischoptera (Carpenter and Richardson, 1968) in the order Megasecoptera.
} 


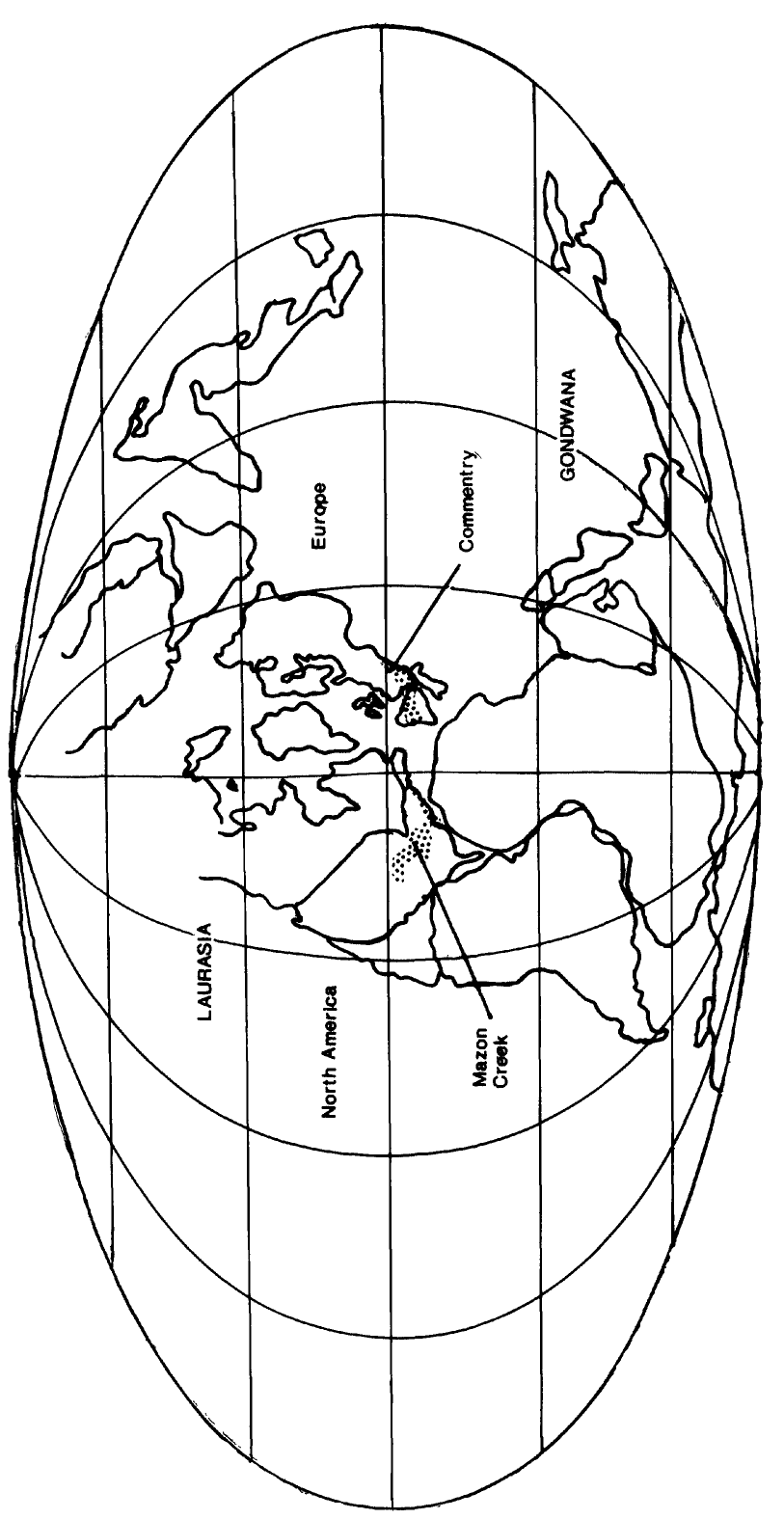

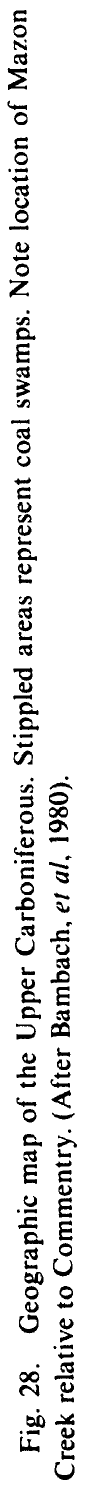




\section{Discussion}

Recognition of the Protorthoptera has had a varied and unsettled history. Despite the unquestioned importance of the order in the evolution of the higher Insecta (as ancestors to extant Orthoptera and possibly to the Holometabola) there is as yet little agreement about affinities within the group. Our understanding of relationships within the order is still rudimentary. This is well documented by the present study in which the families Sthenaropodidae and Geraridae (previously assigned to two distinct orders) are synonymized. Many attempts have been made to separate the Paleozoic Orthopteroidea into more "natural lineages," but it is currently proposed (Carpenter, 1966) that recognition of one order Protorthoptera (sensu lato) is preferable until a better understanding of the group's true phylogeny emerges. While this forces acknowledgement of the Protorthoptera as a "taxonomic wastebasket" and the group "as thus constituted is almost certainly polyphyletic" (Carpenter, 1966), adoption of a presumably phylogenetic classification would, at this time, only misrepresent the actual evolutionary relationships of these insects. I believe that previous work on the Protorthoptera (particularly the Sthenaropodidae) is a good example of how such misrepresentation can occur as the result of inadequate study of a given fossil group.

The Protorthoptera were first recognized in 1906 when Handlirsch split the Paleozoic orthopteroids into three orders: the Protorthoptera, Protoblattodea, and Protorthoptera vel Protoblattodea (for species that seemed to merge the characteristics of the first two). In 1938 the Soviet scholar Martynov made an alternative suggestion: that the fossil Orthopteroidea be divided into the two orders Protorthoptera and Paraplecoptera according to whether they possessed saltatorial legs, as in the Protorthoptera, or cursorial ones, as in the Paraplecoptera. The Geraridae were placed at this time in the Paraplecoptera, and Martynov considered them, on the basis of size and cursorial legs, to be typical representatives of that order. Sharov $(1960,1962)$ originally suggested that these orders be reorganized into the Protorthoptera, Paraplecoptera, and Protoblattodea, but later (1968) expressed agreement with Carpenter that the Paraplecoptera and Protoblattodea cannot be recognized as distinct orders. 
Convinced that the Protorthoptera should reflect direct relationship to the Orthoptera, Sharov narrowed the order to include only a single family, the Sthenaropodidae, synonymized here with the Geraridae. Unfortunately, not having had the opportunity to examine the Commentry types, he erroneously believed that the family consisted entirely of saltatorial forms and used this to justify its placement in the Protorthoptera. The various families previously assigned to the Protorthoptera were placed in the Paraplecoptera (containing the Geraridae), and the true Orthoptera. More complete accounts of these various classifications are given by Carpenter $(1966,1977)$ and Sharov (1968).

The most recent classification of Orthopteroidea was proposed by Rasnitsyn (1980) in his work entitled The Historical Development of the Insecta. Here he distributes the Paleozoic orthopteroids among ten separate orders and proposes a new order Gerarida for which Geraridae is the type family. The order Gerarida includes six Mid to Late Upper Carboniferous families (previously assigned to the Protoblattodea and Paraplecoptera), which Rasnitsyn considered related to one another on the basis of their elongate prothoraces and free, highly mobile heads. He includes in this order the Eucaenidae, Spanioderidae, Dieconeuridae, Ischnoneuridae, Cnemidolestidae, and Geraridae.

Rasnitsyn (1980:165) admits that recognition of the Gerarida and its division into these families is "extremely provisional owing to insufficient study of its members." Inasmuch as this revision of the Geraridae has shown the degree to which detailed study of a particular taxon can affect higher levels of paleoentomological classification, it would seem premature to accept Rasnitsyn's ordinal classification at this time. In my opinion, it is preferable to continue to recognize the Protorthoptera sensu lato until we have valid synapomorphies by which the true monophyletic groups in the Protorthoptera can be recognized.

The relationship of the Geraridae to other Carboniferous Protorthoptera must consequently remain unresolved. Nevertheless, there are several interesting possibilities to consider. The first of these is that Rasnitsyn may be correct in grouping together those families with elongate prothoracic segments. It is perfectly possible that they 
represent a monophyletic offshoot of the Insecta that left no descendants. ${ }^{10}$

Other possible relationships, however, may be construed on the basis of venational characters, particularly the nature of $M$ in the fore wing. This vein is distinctive in that it either anastomoses with RS for a short distance, or is connected to it by a cross vein. Because a similar trend is seen in other groups of Protorthoptera, it may suggest common descent. Families, aside from the Geraridae, known to possess this anastomosis between $\mathrm{M}$ and RS are the Streptocladidae, Oedischiidae, Nugioneuridae, and Tococladidae. While many of these families (particularly the Streptocladidae) have a much more complex venation than the Geraridae, it may be that they represent an earlier stage in the evolution of the group-one that led eventually to the saltatorial forms represented by the oedischiids. Because the oedischiids were clearly saltatorial as far back as the Carboniferous, it is reasonable to speculate that the gerarids fall into a proto-saltatorial complex of Upper Carboniferous Protorthoptera and may represent a line of evolution quite distinct from that of the cursorial orthopteroids living today.

\section{Summary}

The family Geraridae, previously thought restricted to North America, and known only from Mazon Creek, was apparently a widespread and fairly successful group in the Upper Carboniferous. Careful examination of Commentry Protorthoptera has resulted in the synonymy of Sthenaropoda with Gerarus from Mazon Creek and illuminates the problems inherent in the classifications proposed by several recent authors. Recognition of the family Sthenaropodidae as the sole family of the order Protorthoptera and the Geraridae as members of the order Paraplecoptera or Gerarida is no longer tenable.

While further study is required to determine whether the Geraridae are more closely related to the Mazon Creek families considered

\footnotetext{
1"Rasnitsyn is not the first to propose that the elongate prothorax is a synapomorphic character. Others, especially Handlirsch, have already suggested that the Geraridae are close relatives of the Spanioderidae on this basis. An argument against this relationship, however, is the fact that they have distinctly different patterns of venation. (In the Spanioderidae CUA is multiply branched and $\mathbf{R}$ branches only once. Neither character is true for the Geraridae.)
} 
by Rasnitsyn as belonging to the "Gerarida," or to the oedischiid complex of true Orthoptera, at least monophyly for the family is now established. What remains is the task of clarifying the relationships of these other families; not only in terms of their relationships to each other, but to their extant descendants as well.

TABLE 1. Past and Present Classifications of the Geraridae.

Classification proposed by previous workers
Classification proposed by Burnham in this article

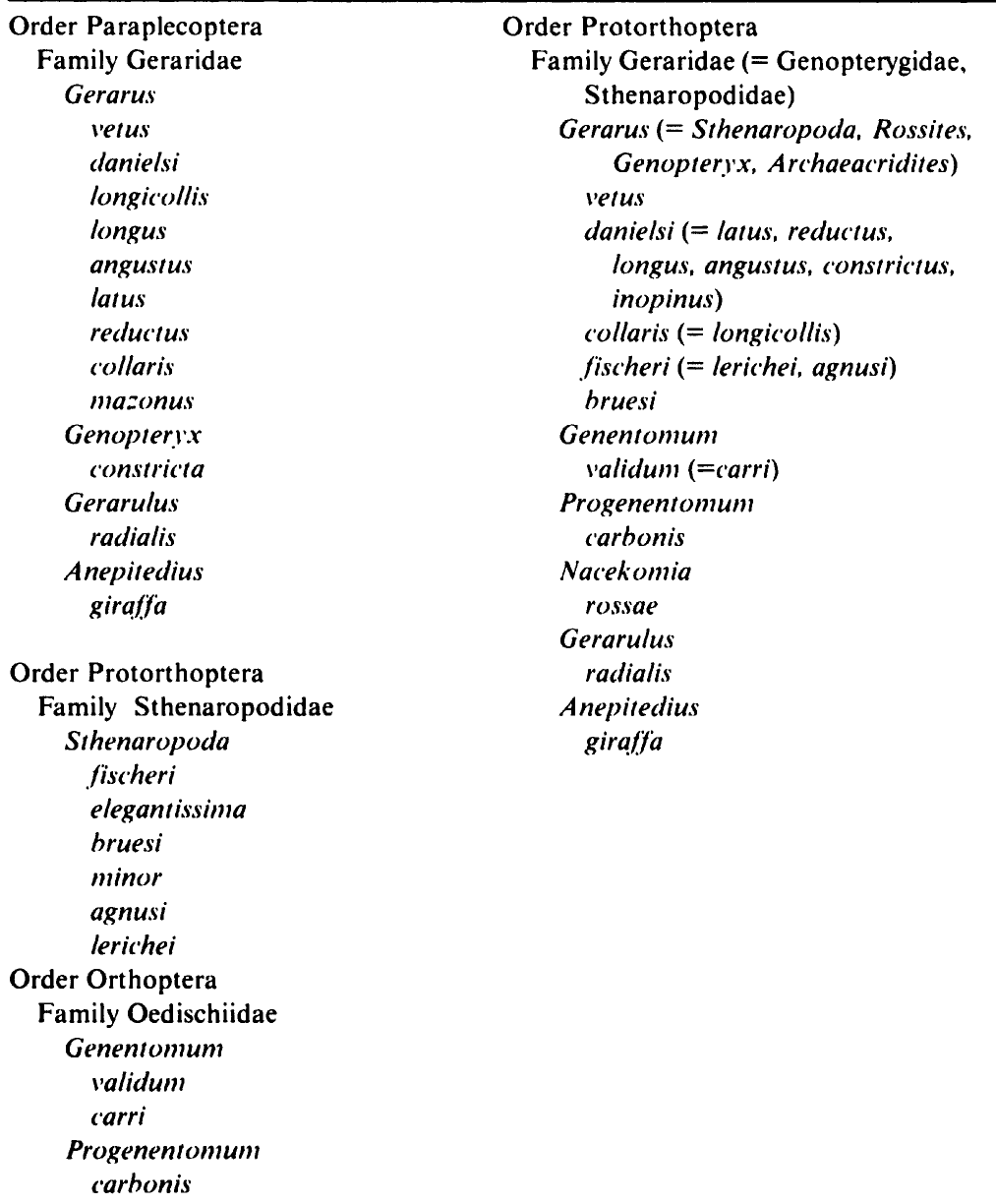




\section{ACKNOWLEDGEMENTS}

Many persons have contributed in varying ways to this paper. I would like to begin by thanking Professor Frank M. Carpenter for his superb advice and guidance. I thank him for his demanding sense of scholarship, his never failing encouragement of my research, and his incredible ability to understand even my most peculiar idiosyncrasies. In honor of his 80th birthday, and in recognition of his role as friend, mentor, and adviser, I dedicate this paper to him.

Robert Mawhinney is a special person and Harvard colleague who deserves thanks for his keen, theoretical mind and inspirational nature, both of which he has so willingly shared with me. I thank him for the spirit with which he has gauged my progress and has offered many helpful, insightful, and nonambiguous suggestions.

Professor James Wilkinson of the History and Literature Department at Harvard has shown strong interest in the Geraridae and provided encouragement and editorial assistance whenever needed. His enthusiasm for paleoentomology and his support of my work have meant a great deal to me.

Dr. E. S. Richardson, Jr., of the Field Museum was particularly helpful in sending unidentified material to me for examination; without this material this revision would have had little significance. His warm and enthusiastic support of my research is gratefully appreciated. His premature death is a great loss to many of us.

Professors W. L. Brown, J. L. Cisne, and G. C. Eickwort of Cornell University read an earlier draft of this manuscript and offered many excellent suggestions for its improvement.

Beverly Strassmann, Dr. Naomi Pierce, and Professors Ruth Temple and Geneva Sayre are colleagues and friends who provided encouragement and support at the right times. They are appreciated in many ways.

Dean John Wootton of Cornell University offered assistance and advice when they were most needed. I am grateful to him for this.

K. M. Horton provided invaluable typing and editing skills. Her standards of excellence have greatly improved this manuscript and I am grateful for her support.

The staff at the Institut de Paleontologie in Paris were warm, helpful, and hospitable during my visit there. In particular, I would like to thank Dr. J. C. Fischer (Directeur), Mme. Yvette Gayrard, 
Dr. Daniel Heyler, and Dr. Agnes Lauriat-Rage for their wonderful assistance.

The following individuals very kindly supplied the specimens on which this study depended: Mr. F. J. Collier of the United States National Museum; Mr. David Douglass of Yachats, Oregon; Mr. Daniel Damrow of Mosineee, Wisconsin; Mme. Y. Gayrard of the Institut de Paléontologie; Mrs. J. S. Lawless of the Yale Peabody Museum; and the late Dr. E. S. Richardson of the Field Museum of Natural History.

Partial financial support of this research is gratefully acknowledged to National Science Foundation Grant no. DEB 82-05398 (F. M. Carpenter, Principal Investigator), the Society of the Sigma Xi, Cornell Chapter, and to Sigma Xi, the Scientific Research Society, for a Grant-in-Aid of Research.

\section{Literature Cited}

Bambach, R. K., C. R. Scotese And A. M. Ziegler.

1980. Before Pangea: The geographies of the Paleozoic world. Amer. Sci. 68:26-38.

BRONGNiART, C.

1885. Les insectes fossiles des terrains primaires. Bull. Soc. Amis Sci. Nat. Rouen, pp. 50-68.

1894. Récherches pour servir à l'histoire des insectes fossiles des temps primaires. Thèse Fac. Sci. Paris, no. 821: 1-494.

BURNHAM, L.

1981. Fossil insects from Montceau-les-Mines (France): A preliminary report. Bull. Soc. Hist. Nat. Autun no. 100: 5-12.

Carpenter, F. M.

1943. Studies on Carboniferous insects from Commentry, France: Pt. I. Introduction and families Protagriidae, Meganeuridae and Campylopteridae. Bull. Geol. Soc. Amer. 54: 527-554.

1964. Studies on North American Carboniferous insects. 3. A spilapterid from the vicinity of Mazon Creek, Illinois (Palaeodictyoptera). Psyche 71(3): 117-124.

1965. Studies on North American Carboniferous insects. 4. The genera Metropator, Eubleptus, Hapaloptera and Hadentomum. Psyche 72(2): $175-190$.

1966. The Lower Permian insects of Kansas. Pt. 11. Psyche 73: 46-88.

1971. Adaptations among Paleozoic insects. Proc. N. Amer. Paleo. Conv., Chicago, 1969, vol. 1, pp. 1236-1251.

1977. Geological history and evolution of the insects. Proc. 15th Int. Congr. Ent., Washington, D.C., 1976, pp. 63-70. 
Carpenter, F. M. and E. S. Richardson, Jr.

1968. Megasecopterous nymphs in Pennsylvanian concretions from Illinois. Psyche 75(4): 295 309.

1971. Additional insects in Pennsylvanian concretions from Illinois. Psyche 78(4): 267-295.

COCKerell, T. D. A.

1917. Fossil insects. Ann. Ent. Soc. Amer. 10(1): 1-22.

FAYOL, $\mathrm{H}$.

1887. Études sur le terrain houiller de Commentry. Première partie: Lithologie et stratigraphie. Bull. Soc. Ind. Min. XV(3\& 4). Synopsis [in] Bull. Geol. Soc. France 16(3) (1889).

HandizRsCh, A.

1906a. Die fossilen Insekten und die Phylogenie der rezenten Formen. Ein Handbuch für Palaeontologen und Zoologen. Leipz.., Engelmann. 1430 pp.

1906b. Revision of American paleozoic insects. Proc. U.S.N.M. 29: 661-820.

1911. New paleozoic insects from the vicinity of Mazon Creek, Illinois. Amer. J. Sci. 31: 297-326.

1919. Revision der palaeozoischen Insekten. Denkschr. Akad. Wiss. Wien Math. Naturw. 96: 1-82 (511-592).

1920. Geschichte, Literatur, Technik, Palaeontologie, Phylogenie, Systematik. Handb. Ent. 3: 118-306.

1922. Insecta palaeozoica [in] Fossilium Catalogus. 1. Animalia, pars 16, C. Diener, ed.. pp. 1230.

Lameere, A.

1917. Revision sommaire des insectes fossiles du Stéphanien de Commentry. Bull. Mus. Paris 23: 141-200.

1922. Sur la nervation alaire des insectes. Bull. Class. Sci. Belgium, 1922: 138-149 (transl. Psyche 30: 123-132, 1930).

Martynov. A. V.

1924. Sur l'interprétation de la nervation et de la tracheation des ailes des Odonates et des Agnathes. Rev. Russ d'Ent. 18: 145-174 (transl. Psyche 37: 245-280, 1930).

1938. Études sur l'histoire géologique et de phylogénie des ordres des insectes (Pterygota). Trav. Inst. Paléont. Acad. Sci. URSS 7: 1-150.

MEUNIER, F.

1909a. Nouveaux insectes du Stéphanien de Commentry. Bull. Mus. Hist. Nat. Paris. 15: $37-49$.

1909b. Nouveaux paleodictyoptères du Stéphanien de Commentry. Ann. Soc. Sci. Bruxelles. 33: 139-140.

1909c. Nouvelles récherches sur les insectes du Terrain Houiller de Commentry. Ann. Paléont. 4: 125-152.

NITEC'KI, M. H.

1979. Mazon Creek fauna and flora: a hundred years of investigation [in] Mazon Creek Fossils, M. Nitecki, ed., Academic Press, pp. 1-13. 
RASNitsin, A. P.

1980. The historical development of the insects. Trans. Paléont. Inst. 175: 1-268.

Richardson, E. S., JR.

1956. Pennsylvanian invertebrates from the Mazon Creek area, Illinois. (Insects). Fieldiana Geol. 12: 15-56.

SCIDDER, S. H.

1885. Palaeodictyoptera: on the affinities and classification of Paleozoic Hexapoda. Mem. Boston Soc. Nat. Hist. 3: 319-351.

1890. The fossil insects of North America, vol. I. The pretertiary insects. SHAROV, A. G.

1960. On the system of the orthopterous insects. Int. Congr. Ent., Wien, 1960, vol. I, pp. 295-296.

1962. The order Protorthoptera [in] Osnovy paleontologii, B. Rohdendorf, ed., Moscow, pp. 145-146.

1968. Phylogeny of orthopteroid insects. Tr. Paleontol. Inst. Akad. Nauk SSSR 118: 1-218. (In Russian. English transl. 1971, Israel Program Sci. Transl. Ltd., 251 pp.)

Stevenson, J. J.

1909. The coal basin of Commentry in central France. Ann. N. Y. Acad. Sci. 19(2): 161-204.

WoOdland, B. G. and R. C. Stenstrom

1979. The occurrence and origin of siderite concretions in the Francis Creek Shale (Pennsylvanian) of northeastern Illinois [in] Mazon Creek Fossils, M. Nitecki, ed., Academic Press, pp. 69-104.

Wootton, R. J.

1979. Function, homology and terminology in insect wings. Syst. Ent. 4: 81-93.

1981. Palaeozoic insects. Ann. Rev. Ent. 26: 319-344. 

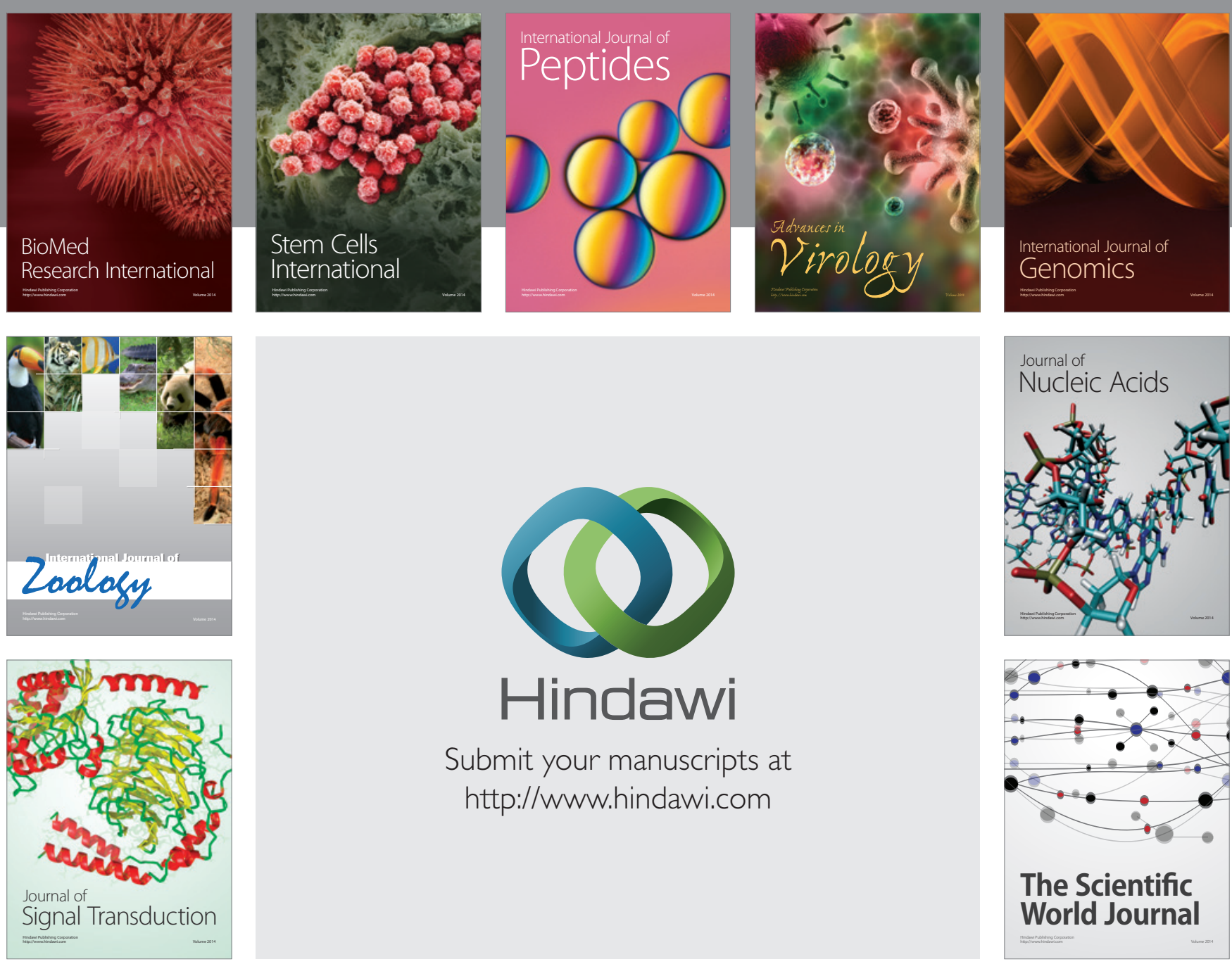

Submit your manuscripts at

http://www.hindawi.com
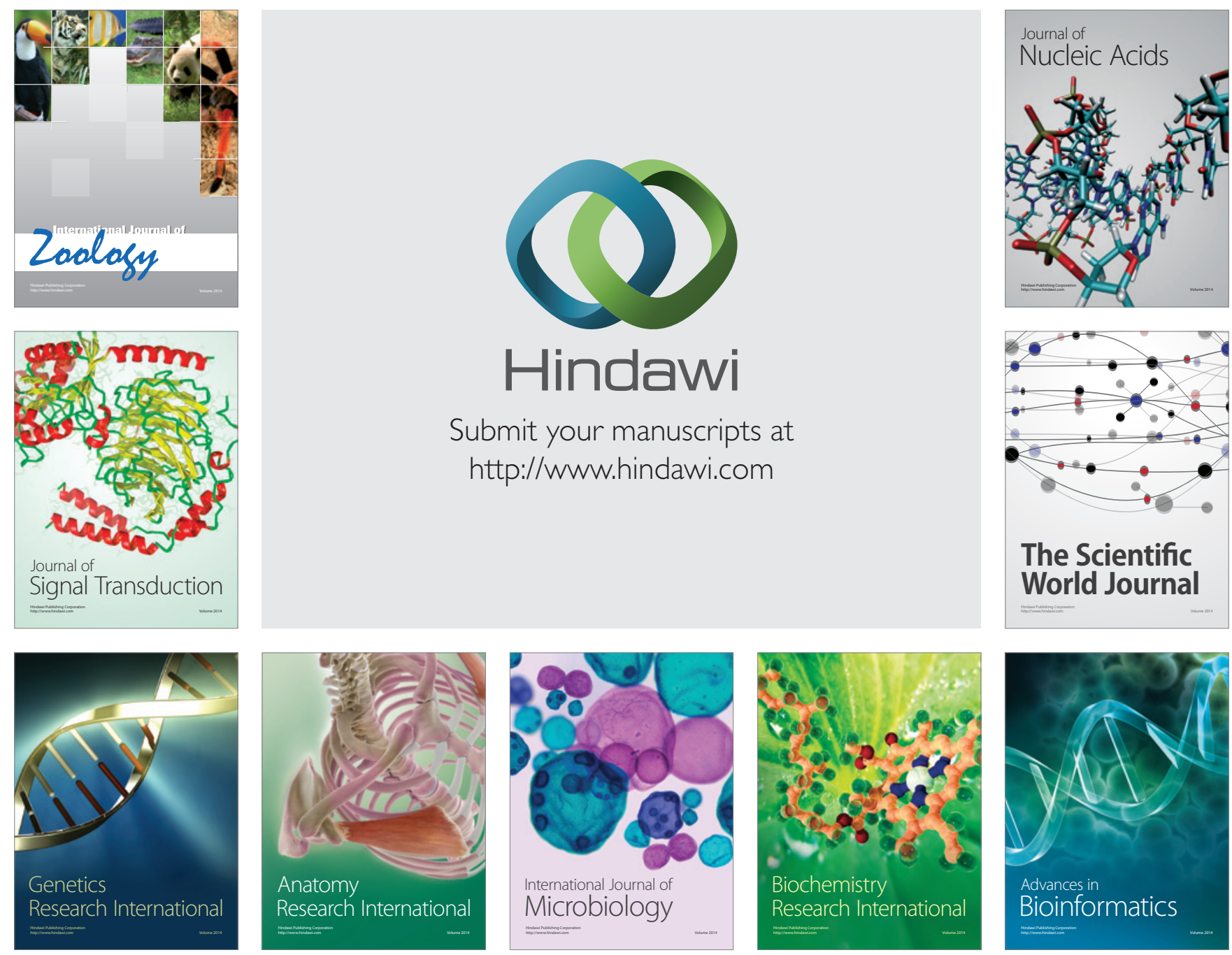

The Scientific World Journal
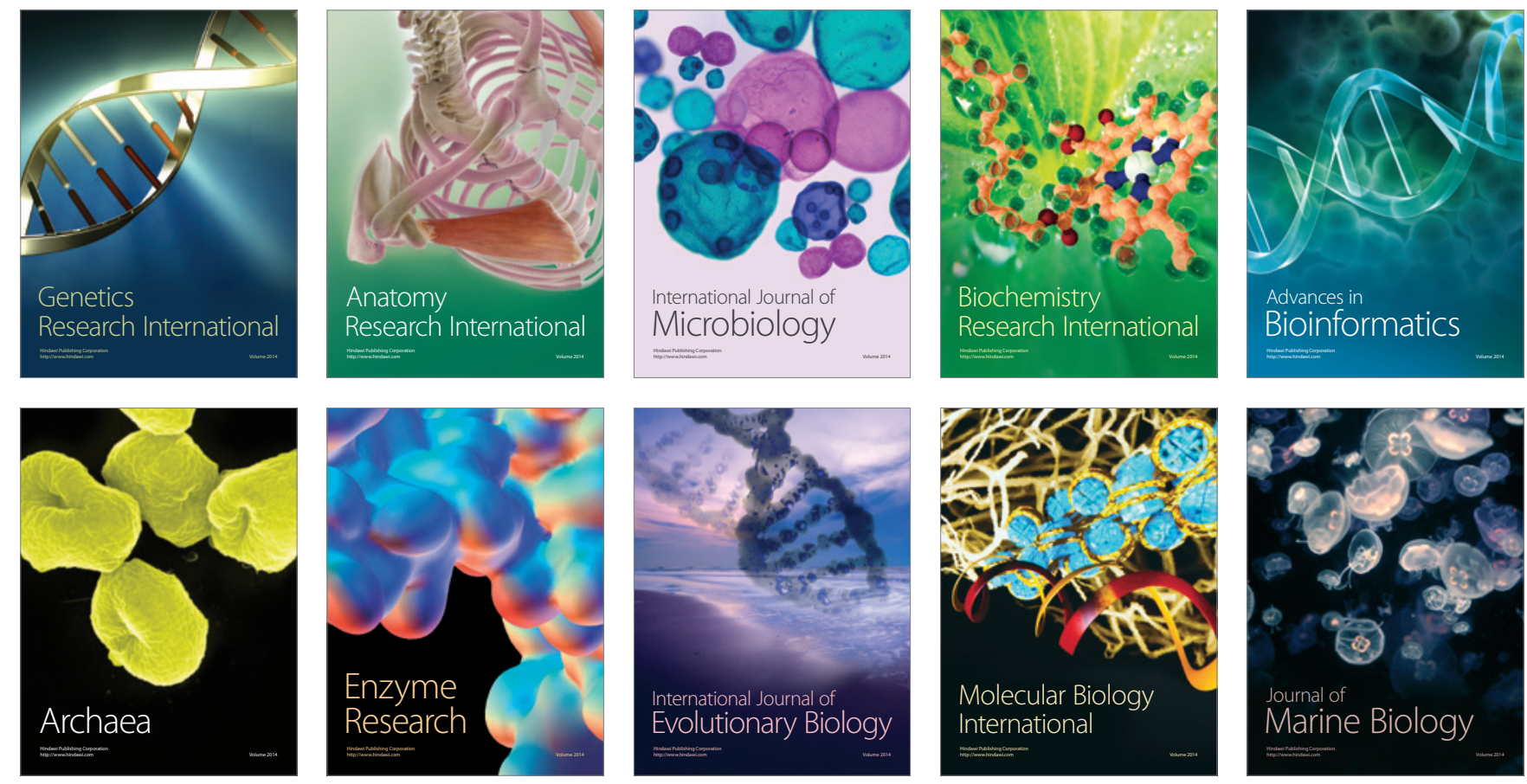